NBER WORKING PAPER SERIES

\title{
THE IMPACT OF THE PHILADELPHIA BEVERAGE TAX ON PURCHASES AND CONSUMPTION BY ADULTS AND CHILDREN
}

\author{
John Cawley \\ David Frisvold \\ Anna Hill \\ David Jones \\ Working Paper 25052 \\ http://www.nber.org/papers/w25052 \\ NATIONAL BUREAU OF ECONOMIC RESEARCH \\ 1050 Massachusetts Avenue \\ Cambridge, MA 02138 \\ September 2018
}

We thank Hunt Allcott, Ronette Briefel, Jason Fletcher, Tina Kauh, Jayson Lusk, Erich Muehlegger, Shiriki Kumanyika, Mary Story, and participants at the American Society of Health Economists conference for their helpful comments. We thank Nancy Clusen, Jon Gellar, Mindy Hu, Jeannette Holdbrook, Kim Mook, Tyler Rose, and Eric Zeidman for their assistance with the data collection and analysis. We gratefully acknowledge funding from the Robert Wood Johnson Foundation. The views expressed herein are those of the authors and do not necessarily reflect the views of the National Bureau of Economic Research.

NBER working papers are circulated for discussion and comment purposes. They have not been peer-reviewed or been subject to the review by the NBER Board of Directors that accompanies official NBER publications.

(C) 2018 by John Cawley, David Frisvold, Anna Hill, and David Jones. All rights reserved. Short sections of text, not to exceed two paragraphs, may be quoted without explicit permission provided that full credit, including $\odot$ notice, is given to the source. 
The Impact of the Philadelphia Beverage Tax on Purchases and Consumption by Adults and Children

John Cawley, David Frisvold, Anna Hill, and David Jones

NBER Working Paper No. 25052

September 2018

JEL No. H2,H71,H75,I12,I18

\section{$\underline{\text { ABSTRACT }}$}

In recent years, numerous U.S. cities have enacted taxes on sweetened beverages, but there is relatively little evidence about the effects of these taxes on purchases and consumption. In this paper, we examine the effects of the beverage tax of 1.5 cents per ounce that was implemented in Philadelphia starting January 1, 2017. We surveyed individuals in Philadelphia and nearby comparison communities before the tax and nearly one year after implementation of the tax about their purchases and consumption of beverages. We find that purchases of taxed beverages fell by 8.9 ounces per shopping trip in Philadelphia stores relative to comparison stores outside of the city and that Philadelphia residents increased purchases of taxed beverages outside of the city. The tax reduced adults' frequency of regular soda consumption by 10.4 times per month, and there is some evidence of a slight reduction in adults' overall sugar consumption from sweetened beverages, with larger reductions for African-American adults. The tax did not have a substantial effect on the frequency of adults' consumption of other beverages. We generally do not find detectable effects of the tax on children's consumption of beverages, although we find a substantial reduction in consumption of added sugars from sweetened beverages among children who had high pre-tax consumption levels.

John Cawley

2312 MVR Hall

Department of Policy Analysis and Management and Department of Economics

Cornell University

Ithaca, NY 14853

and NBER

JHC38@ cornell.edu

David Frisvold

Department of Economics

University of Iowa

21 East Market Street

Iowa City, IA 52242

and NBER

david-frisvold@uiowa.edu
Anna Hill

Mathematica Policy Research

955 Massachusetts Avenue

Suite 801

Cambridge, MA 02139

ahill@mathematica-mpr.com

David Jones

Mathematica Policy Research

955 Massachusetts Avenue

Suite 801

Cambridge, MA 02139

DJones@mathematica-mpr.com 


\section{Introduction}

Countries worldwide have experienced a rapid increase in the prevalence of diet-related chronic diseases. For example, the worldwide age-standardized prevalence of obesity rose from 3.2 to 10.8 percent among men and from 6.4 to 14.9 percent among women, between 1975 and 2014 (NCD Risk Factor Collaboration, 2016a). The age-standardized prevalence of diabetes has also risen considerably worldwide, increasing from 4.3 to 9.0 percent among men and from 5.0 to 7.9 percent among women, between 1980 and 2014 (NCD Risk Factor Collaboration, 2016b). Within the United States, the prevalence of adult obesity rose from 22.9 percent to 39.6 percent, and the prevalence of childhood obesity rose from 10.0 percent to 18.5 percent between 19881994 and 2015-2016 (Fryar, Carroll, and Ogden, 2016a, 2016b; Hales, Carroll, Fryar, and Ogden, 2017). Moreover, rates of obesity vary across the population. Among both adults and children, the prevalence of obesity is highest among African-American and Hispanic individuals (Hales et al., 2017).

In response, governments have debated policies to improve diets and population health. There is particular concern about the role of sugar-sweetened beverages (SSBs), which now represent the primary source of added sugars in the U.S. diet (Malik and Hu, 2011). Because they are fluids with simple carbohydrates and therefore are metabolized quickly, SSBs do not cause feelings of satiation and thus contribute empty calories to a higher overall calorie intake (Malik and Hu, 2011). SSBs also contribute to a high glycemic load, which leads to insulin resistance and diabetes (Malik and $\mathrm{Hu}, 2011)$.

One common policy recommendation for reducing sugar intake and obesity is a tax on SSBs. For example, in 2016, the World Health Organization (WHO) recommended taxes on SSBs as a key measure for addressing childhood obesity (WHO, 2016). Numerous countries have implemented taxes on SSBs, including Belgium, Chile, Fiji, Finland, France, Mexico, Norway, Saudi Arabia, Spain, Tonga, and the United Kingdom (Thow et al., 2018). Also, since 2015, a number of U.S. cities have implemented taxes on SSBs, including Berkeley, California; Philadelphia, Pennsylvania; Boulder, Colorado; San Francisco, California; and Seattle, Washington. Yet, there is little rigorous evidence about the effects of such taxes, especially on purchases and consumption.

In this paper, we estimate the impact of the beverage tax in Philadelphia, Pennsylvania, on purchases and consumption. The Philadelphia beverage tax was implemented on January 1, 
2017. The amount of the tax is 1.5 cents per ounce, and, uniquely among beverage taxes in U.S. cities, it is levied on sweetened caloric beverages (such as regular soda) and sweetened noncaloric beverages (such as diet soda). Unsweetened beverages (such as bottled water), 100 percent fruit juices, and beverages that are at least 50 percent milk (such as chocolate milk) are untaxed. The tax was fully passed through to consumers, raising prices by 1.6 cents per ounce, on average, across all taxed beverages (Cawley, Frisvold, Hill, and Jones, 2018a). The passthrough rate was higher in stores closest to the center of the city that were farther from competitors selling untaxed beverages, and was higher among stores in higher poverty neighborhoods. Furthermore, after the tax was implemented, stores in Philadelphia increased the availability on shelves of untaxed beverages, particularly bottled water, and decreased the availability of taxed beverages (Cawley et al., 2018a). The shift to healthier beverages could also influence households' consumption by changing the relative availability of healthy and unhealthy beverages.

There exists one previous study of the impact of the Philadelphia beverage tax on consumption. Zhong et al. (2018) conducted a phone survey before the tax (December 2016) and shortly after the tax (January and February 2017) in Philadelphia and three nearby comparison cities (Trenton, New Jersey; Camden, New Jersey; and Wilmington, Delaware). Based on the repeated cross-sections, the authors estimate that the probability of daily consumption of regular soda fell 40 percent, the probability of daily energy drink consumption fell 64 percent, and the probability of daily consumption of bottled water rose 58 percent. There were no changes in daily consumption of SSBs or diet beverages; in the total volume consumed in the past 30 days of SSBs (or any type of SSBs), diet beverages, or bottled water; or in the 30day consumption frequency for any type of beverage, except regular soda.

The only other evidence on the impact of SSB taxes on consumption in the United States comes from the tax of one cent per ounce in Berkeley. Falbe et al. (2016) estimate that, among adults in Berkeley (relative to Oakland and San Francisco), the frequency of SSB consumption fell by 24 percent, and the frequency of bottled water consumption rose by 37 percent. Other studies have attempted to estimate the effect on consumption of national SSB taxes, but they 
lacked a geographic control group and thus could not isolate the impact of the taxes from changes that would have occurred in absence of the taxes. ${ }^{1}$

To understand the effect of the Philadelphia beverage tax on consumption, we first examined changes in purchases. We interviewed consumers exiting a representative sample of retail stores in Philadelphia and a comparable set of stores outside of Philadelphia (in the surrounding counties within Pennsylvania's Metropolitan Statistical Area (MSA)), to determine the volume of taxed and untaxed beverages purchased. Based on repeated cross-sections, we compared the change in purchases among consumers at stores in Philadelphia before and after the tax with the change in purchases among consumers at stores in the comparison communities over the same time period. Purchases decreased at stores in Philadelphia and increased at stores outside of Philadelphia, resulting in a relative decrease of 8.9 ounces of taxed beverages purchased per shopping trip in Philadelphia. The relative change in purchases did not occur because the tax increased the likelihood that Philadelphia residents shopped outside of the city. Instead, Philadelphia residents who already shopped outside of the city shopped there more frequently and purchased more SSBs outside of Philadelphia nearly one year after the tax was implemented.

We next examined the effect of the tax on consumption of taxed and untaxed beverages and added sugars from SSBs. Based on the interviews with consumers exiting stores in Philadelphia and the comparison communities, we enrolled one adult and one child from each household in a longitudinal survey of consumption, with a baseline survey 1 to 2 months before the tax and a follow-up survey 10 to 11 months after the tax was implemented. For children, we find that the tax did not impact beverage consumption, on average. However, for children who were high consumers of SSBs, the tax substantially reduced consumption. The tax decreased the intake of added sugars by 14.7 grams per day or 22 percent for children who consumed 67 grams of added sugars daily, or approximately one 20 ounce bottle of regular soda each day, prior to the tax.

For adults, the tax decreased the frequency of regular soda consumption by approximately 10 times per month and reduced the probability that an adult in Philadelphia

\footnotetext{
${ }^{1}$ Additionally, Fletcher, Frisvold, and Tefft (2010; 2015) examine the impact of smaller state taxes on soda in the United States on consumption among children and adults. There are also many studies of the price elasticity of demand for beverages (e.g., Powell et al., 2013) and of the potential impact of SSB taxes based on demand models (e.g., Dubois, Griffith, and O’Connell, 2017).
} 
consumed regular soda daily by 11 percentage points or approximately 31 percent. We do not find evidence of substantial changes in consumption of other beverage types among adults. However, we find some evidence of a slight reduction in consumption of sugars from SSBs among adults of approximately 6 fewer grams per day.

We further investigate heterogeneous responses of the tax on consumption among demographic groups with particularly high rates of obesity (e.g., African-American and Hispanic adults and children) and groups for which we might expect to have stronger responses to the tax (e.g., those that are less likely to shop for beverages outside of the city and those trying to consume fewer SSBs). We also examine the effect of the tax on households living in poverty and those receiving public assistance, as there is evidence that the elasticity of demand for SSBs varies by income and demographics (Lin et al., 2011). In general, we do not find consistent and precisely-estimated effects of the tax for subgroups, with a few exceptions. Namely, we find that the tax decreased consumption for African-American adults and children and adults who view SSBs as bad for their health.

This paper makes several key contributions to the literature. It provides the first estimates of the impact of SSB taxes on children's consumption. Past studies of city-level beverage taxes have estimated effects on consumption only for adults. ${ }^{2}$ Second, the study is the first to use longitudinal survey data to estimate the impact of a city-level tax on consumption of SSBs; the previous studies of Philadelphia and Berkeley both used repeated cross-sections. Using the longitudinal data, we are able to examine whether the impact of the tax varies based on level of pre-tax consumption. Third, we estimated the impact on consumption 10 to 11 months after the tax; the earlier studies used data from 1 to 2 months after the Philadelphia tax and from 1 to 5 months after the Berkeley tax. Examining data 10 to 11 months after a tax may provide a better sense of the longer-term, post-adjustment effects. Finally, we examined changes in beverage purchases and the location of the purchases to understand any impact of the tax on cross-border shopping.

In the next section, we summarize the primary data collection conducted to support the examination of the impacts on purchases and consumption. In Section III, we present the analysis

\footnotetext{
${ }^{2}$ Fletcher, Frisvold, and Tefft (2010) find that smaller state taxes on soft drinks reduced soft drink consumption among children but increased consumption of other high-calorie drinks. No previous papers have examined the consumption responses of children to the recent, larger taxes on SSBs.
} 
of purchases (including an examination of cross-border shopping), beginning with a description of the methodology and concluding with the results. In Section IV, we present the analysis of consumption, again beginning with a summary of the methodology followed by the results. We conclude with a discussion of the findings and implications of the results for future beverage tax policies and related research.

\section{Data}

To examine the beverage tax’s influence on purchases and cross-border shopping and its impact on consumption, we collected cross-sectional data from consumers at stores in Philadelphia and comparison communities about their beverage purchases prior to and after implementation of the tax, and then conducted a household survey of beverage consumption prior to and after implementation of the tax among adults and children living in Philadelphia and the same comparison communities. The data collection followed a nested design in which we collected data from stores, consumers, and households in Philadelphia and comparison communities adjacent to the city before and after implementation of the tax. We first selected stores, then selected adult customers exiting those stores for interviews, and finally identified customers living in households with children to participate in the household survey. We selected a representative set of stores, based on sales volume, in Philadelphia and a matched comparison group of stores in the counties adjacent to Philadelphia (Delaware, Montgomery, and Bucks counties; the city of Philadelphia is coterminous with the county of Philadelphia). ${ }^{3}$ The sample of stores provided the location for recruitment of consumers and households to participate in two phases of data collection. First, we interviewed consumers exiting the stores and collected information on their demographics and purchases; 12 months later, we interviewed a second round of consumers about their purchases to support the analysis of purchases and cross-border shopping using repeated cross-sections. Second, using the exit interviews of consumers prior to the tax, we recruited consumers to participate in a longitudinal survey (one adult and child per

\footnotetext{
${ }^{3}$ We matched each store in the Philadelphia sample to a store of the same type in the comparison communities with the closest score on a composite measure of the three local population characteristics (percentage African-American, percentage Hispanic, and percentage of households in poverty in the neighborhood where the store is located). The approach should also result in a pool of possible consumers and households for the purchases and consumption analyses that who shop at the same types of stores and have similar percentages who are African-American, Hispanic, and in households below the federal poverty level (FPL). For further details about the store sample, see Cawley et al. (2018a).
} 
household) on beverage consumption and related attitude and behavior measures to support the analysis of the impacts on consumption.

\section{a. Exit interviews (repeated cross-sectional data on purchases)}

We collected information from consumers as they exited stores. First, since children's beverage consumption is of particular policy interest, we initially asked consumers several screener questions to identify adults age 18 and older who lived in a household with at least one child between 2 and 17 years of age, located in Philadelphia or one of the adjacent counties. As a result, the cross-sectional sample is representative of households with children, after applying survey weights, but it is not a representative sample of all households in Philadelphia. For consumers meeting these criteria, we recorded: (1) the quantity, size, and name of each beverage they purchased; (2) basic demographic information (age, gender, race, ethnicity, household size, and income); (3) whether they lived in Philadelphia; and (4) whether the store at which they were interviewed was their usual source of beverage purchases. ${ }^{4}$ The main outcomes for the analysis of purchases are the volume of taxed and untaxed beverages purchased by consumers. ${ }^{5}$ We also constructed the volume of soda and water purchases, which are among the most commonly purchased taxed and untaxed beverage types, based on the beverage names. Finally, we collected consumers' contact information and signed them up to respond to the longitudinal household survey.

Collecting purchase information through exit interviews at stores has two advantages over collecting the information through the household survey. First, we collected the information immediately after the beverages were purchased. We directly observed the beverages consumers purchased when they exited the store or asked consumers to self-report their purchases, which minimized or avoided measurement error caused by recall bias or misreporting that could occur in a survey conducted days or weeks after purchases are made. Second, by observing where the purchases occurred and recording where consumers lived, we are able to directly examine changes in cross-border shopping among Philadelphia residents.

\footnotetext{
${ }^{4}$ We collected information on all beverages that consumers purchased from out-of-pocket expenditures, SNAP benefits, and WIC benefits.

${ }^{5}$ We coded beverages as taxed or untaxed based on a manual review of the beverage names that were directly observed by interviewers or self-reported by consumers. If we were not able identify the volume for all beverages purchased by a consumer, then we recorded the value for the volume of purchases for that shopping trip as missing.
} 
We collected the information from cross-sections of consumers visiting the stores at two points in time, one year apart: November to December 2016 (pre-tax) and November to December 2017 (post-tax). We interviewed consumers in the same months in both years because beverage purchases may be seasonal. We selected the time of the day (within the stores' operating hours) and day of the week for interviews at random, and we interviewed consumers at all times of the day and every day of the week to capture the range of consumers visiting the stores.

For Philadelphia, the sample includes 600 interviews in 2016 (44.5 percent purchased a beverage, 25.3 percent purchased a taxed beverage, and 10.1 percent purchased an untaxed beverage) and 763 interviews in 2017 (46.5 percent purchased a beverage, 29.7 percent purchased a taxed beverage, and 14.1 percent purchased an untaxed beverage). In the comparison areas (outside the city but within the Philadelphia MSA), the sample includes 705 interviews in 2016 (37.0 percent purchased a beverage, 21.3 percent purchased a taxed beverage, and 10.0 percent purchased an untaxed beverage) and 738 interviews in 2017 (43.8 percent purchased a beverage, 29.7 purchased a taxed beverage, and 11.5 percent purchased an untaxed beverage). We successfully collected information from over 90 percent of consumers we approached at stores in Philadelphia and at comparison stores in both time periods.

\section{b. Household survey (longitudinal data on consumption)}

In the period before the implementation of the tax, we contacted all consumers who completed an exit survey and who agreed to provide their contact information. Among Philadelphia residents, 46.2 percent of consumers completing an exit interview also completed the household survey; 50.2 percent completed the survey among households living in the comparison communities. We followed up with households that completed the survey in the pretax period roughly one year later to have them complete the survey after the implementation of the tax. We collected the information on the same timeline as the exit interviews, with the baseline, pre-tax survey in November and December 2016 and the follow-up, post-tax survey in November and December 2017. The number of households that responded to both waves of the survey was 241 in Philadelphia (65.9 percent of those that responded at baseline) and 199 in the nearby comparison communities (62.3 percent of those that responded at baseline). We classified 
households according to their original location; four households moved out of, and two households moved into, Philadelphia.

Through the survey, which was administered online with follow-up by telephone, we collected detailed information on beverage consumption for the adult respondent and a randomly chosen child within the household. We surveyed children over 12 years of age directly; parents responded for younger children and any older children who could not be reached directly. ${ }^{6}$ In addition, we collected information on beverage shopping patterns, attitudes toward the tax and SSBs, and individual and household characteristics. We measured beverage consumption using the National Health and Nutrition Examination Survey (NHANES) Dietary Screener Questionnaire (DSQ), which has been validated for adults and children 2 years of age and older. We used the responses in the survey to measure the frequency of beverage consumption for a range of taxed and untaxed beverage types over the past 30 days. In addition, we constructed the total amount of added sugars consumed from beverages as a summary measure of consumption, using the National Cancer Institute (NCI) algorithm developed for the DSQ. The algorithm uses age, gender, and the self-reported frequency of consumption of SSBs to estimate the daily intake of added sugars from beverages for both adults and children 2 years of age and older. ${ }^{7}$

\section{Analysis of beverage purchases and cross-border shopping}

\section{a. Methods}

We use the information collected on beverage purchases at stores in Philadelphia and comparison communities to examine how consumers changed the volume of their purchases per shopping trip and the location of their purchases. First, we estimate the changes in the mean volume of taxed and untaxed purchases in Philadelphia stores relative to the matched stores in communities adjacent to Philadelphia. We then control for the characteristics of the consumers and stores in a regression framework. However, if a consumer switched from purchasing SSBs in Philadelphia to outside of Philadelphia, the difference-in-differences (DiD) estimate would

\footnotetext{
${ }^{6}$ For households living in Philadelphia, 83.1 percent of child responses were conducted by the adult respondent; in the households in comparison communities, 83.8 percent of child responses were conducted by the adult respondent. For children over 12 years of age, roughly one-third of the responses were ultimately conducted by the adult respondent in Philadelphia and comparison communities.

${ }^{7}$ The parameters in the algorithm are based on estimates of the amount of each serving size consumed for each beverage type (e.g., regular soda) in a given consumption period, which are based on responses to the What We Eat in America 24-hour dietary recall module from the 2009-2010 NHANES (National Cancer Institute, 2009-2010).
} 
double-count the decrease in purchases within Philadelphia and the increase in purchases outside of the city. Thus, cross-border shopping would amplify the estimate of the relative change in purchases per shopping trip by consumers in Philadelphia. We estimate the extent of crossborder shopping using observations and self-reported responses about where Philadelphia residents shop and what they purchased before and after the tax.

\section{$\underline{\text { Relative changes in purchases }}$}

We estimate the relative change in beverage purchases in Philadelphia using a DiD design, which compares the change in purchases at stores in Philadelphia to those in stores in comparison (or control) communities. The DiD equations are of the general form:

$$
Y_{i s t}=\alpha_{0}+\alpha_{1} \text { Post }_{t}+\alpha_{2} \text { Phila }_{s}+\alpha_{3} \text { Phila }_{s} * \text { Post }_{t}+\alpha_{4} S_{s}+\alpha_{5} X_{i t}+\varepsilon_{i s t} \text {, }
$$

where $Y_{\text {ist }}$ is the volume in ounces of taxed or untaxed beverages for individual $i$ in store $s$ in time period $t$. Phila is a binary variable equal to 1 if the store is in Philadelphia and equal to 0 if the store is in a comparison area. To clarify, this variable is defined based on the location of the store where the consumer was interviewed; it is not based on the residence of the consumer. Post indicates that an observation occurred after the tax took effect. $S_{s}$ is a vector of indicators for store type: stand-alone convenience stores, gas stations with convenience stores, small grocery stores, pharmacies, and warehouse stores; large grocery stores are the omitted store type. ${ }^{8} X_{i t}$ is a vector of consumer and interview characteristics: age, gender (indicator for female), indicator for African-American, indicator for Hispanic, household size, indicator for the household being below the federal poverty level (FPL), indicators for day of the week, and an indicator for whether the household is in Philadelphia. $\alpha_{3}$ is the coefficient of interest and represents the change in the volume of beverages purchased per shopping trip before the tax to after the tax, in Philadelphia relative to the comparison communities. The regressions are

\footnotetext{
${ }^{8}$ As described in Cawley et al. (2018a), we define store types using NAICS codes: convenience stores (445120); gas stations with convenience stores (447110); warehouse clubs and supercenters (452910); pharmacies and drug stores (446110); large grocery stores (445110), which are supermarkets and other grocery stores with annual sales equal to or greater than $\$ 750,000$; small grocery stores (445110), which are supermarkets and other grocery stores with annual sales less than $\$ 750,000$. Note that we restricted pharmacies to three chains (CVS, Rite Aid, and Walgreens) due to the difficulty of identifying pharmacies that sold beverages.
} 
estimated using ordinary least squares. ${ }^{9}$ We cluster the standard errors at the store level to account for correlations between observations within stores. ${ }^{10}$ All results are estimated using sample weights at the consumer level, which account for sample design, oversampling, and nonresponse. ${ }^{11}$

We estimate the relative change in purchases separately for taxed and untaxed beverages. Consumers may treat untaxed beverages as substitutes for the taxed beverages, leading to a shift in demand for the untaxed beverages and increasing purchases. The elasticity of demand may vary by product, so we also estimate regressions separately by beverage type. We estimate the relative changes for one taxed beverage type (soda-regular and diet combined) and one untaxed beverage type (water).

We further estimate whether the relative change in purchases varied by the characteristics of consumers. We focus on four characteristics: whether the consumer is African-American, Hispanic, living in a household that is below the FPL, and living in Philadelphia. Finally, we estimate the differential effect for consumers that were Philadelphia residents, whom we observe at the taxed stores in Philadelphia and the comparison stores outside of the city. If Philadelphia residents were more likely to cross the city border to purchase SSBs after the tax, the overall DiD estimate will reflect this behavior (i.e., we will observe reductions at Philadelphia stores and increases outside of Philadelphia, for an overall larger negative DiD estimate). We estimate the differential changes in purchases for these groups by including interaction terms of the DiD term $\left(\right.$ Phila $_{\mathrm{s}} *$ Post $\left.\mathrm{t}\right)$ and the given subgroup variable. For example, we estimate the change for

\footnotetext{
${ }^{9}$ Because of the high percentage of consumers who did not purchase any beverage (57.0 percent) and the skewed distribution of the volume of beverages purchased (the maximum volume purchased was over 2,000 ounces), we also estimate two-part models in which the first equation estimates whether a consumer purchased a beverage and the second equation estimates the volume of purchases conditional on a purchase. We estimated general linear models with a log-link and Gaussian family for the second equation because of the skewed distribution of the volume of purchase. However, the impact estimates and standard errors were nearly identical to the OLS estimates. We report the OLS estimates in this paper.

${ }^{10}$ With only two geographic regions, standard errors that are clustered at the geographic level would be degenerate (Donald and Lang, 2007). We cluster standard errors at the store level to account for the sampling design, which we described in Section II, but we acknowledge the possibility that these standard errors overstate the precision of the estimates.

${ }^{11}$ The weights take into account the multistage sample design, which begins with the selection of stores. We randomly selected stores and then randomly selected consumers within stores. The weights reflect the probability that the store was selected for our sample and the probability that the consumer was selected within each sampled store. The selection of consumers occurred during a random time window on a random day of the week, which is also accounted for in the weights. Moreover, the weights take into account nonresponse for both stores and consumers. The store nonresponse occurs if a store refuses to allow us to talk with consumers, and consumer nonresponse occurs if the consumer refuses the interview request.
} 
households living below the FPL relative to those living above it by interacting an indicator variable for those living below the FPL with the DiD term in the model.

\section{Cross-border shopping}

We also examine more directly the extent to which there was a change in cross-border shopping — in particular, an increase in Philadelphia residents shopping for beverages outside of Philadelphia. Given the large price increases in taxed beverages as a result of the tax, Philadelphia residents might be more likely to cross the city border to purchase beverages at lower prices at stores not subject to the tax. The degree to which Philadelphia residents responded in this way depends on their price elasticity of demand for taxed beverages and their ability to shop at a store outside of Philadelphia. In addition, untaxed options are generally fairly close for Philadelphia residents (the closest untaxed store is 3.2 miles away from stores in our sample, on average), and shopping outside of the city was fairly common before the tax (17.4 percent of consumers at comparison stores were Philadelphia residents before the tax, and 27.6 percent reported shopping outside of the city one or more times per week). We examine crossborder shopping using two pieces of information from the exit surveys before and after implementation of the tax: (1) observed purchases of consumers who lived in Philadelphia but were shopping outside of Philadelphia (and vice versa) and (2) self-reported frequency of crossborder shopping of consumers at stores in and outside of Philadelphia.

First, we estimate three changes from before to after implementation of the tax that indicate the degree of cross-border shopping among consumers interviewed at comparison stores outside of Philadelphia. We estimate: (1) the change in the percentage of consumers that are Philadelphia residents; (2) the change in the percentage of Philadelphia residents that purchased beverages that are taxed in Philadelphia at these stores; and (3) the change in the volume of taxed beverages purchased by Philadelphia residents. We estimate equations similar to equation (1), using only observations of shopping trips in the comparison areas. The outcome variables are whether the consumer is a Philadelphia resident, whether the Philadelphia resident purchased a beverage that would be taxed in Philadelphia, and the volume of taxed beverages purchased by the Philadelphia resident. We exclude observations from stores in Philadelphia (and observations from non-Philadelphia residents for the second and third outcomes); thus, we remove the indicator variable $P$ hila $a_{\mathrm{s}}$ and the interaction $\left(\right.$ Phila $_{\mathrm{s}} *$ Post $\left._{\mathrm{t}}\right)$ from the equation. The 
coefficient for Post $t_{t}$ is the coefficient of interest; represents the change from before the tax to after the tax. We estimate the regressions using logistic regression for the binary outcomes and ordinary least squares when the outcome is volume. We cluster standard errors at the store level to account for correlations between observations within stores.

Second, we estimate the change in self-reported frequency of shopping across the city border among those interviewed as they exited Philadelphia and comparison stores. We asked consumers exiting stores in Philadelphia how frequently they shopped for beverages outside of the city (never, less than once a week, once a week, or more than once a week). Similarly, we asked consumers exiting stores outside of Philadelphia how frequently they shopped for beverages in Philadelphia. We define the outcome for this analysis as a binary indicator of whether the respondent shops in the given location once or more per week. We estimate the changes separately for Philadelphia residents and those living outside of the city. For example, we estimate the change in the likelihood that Philadelphia residents interviewed at a store in Philadelphia responded that they shop for beverages one or more times per week outside of Philadelphia. ${ }^{12}$ The equations take the form of equation (1), excluding the indicator variable Phila $a_{\mathrm{s}}$ and the interaction (Phila $a_{\mathrm{s}} *$ Post $_{\mathrm{t}}$ ), and are estimated using logistic regression.

\section{b. Results}

The respondents in the exit interviews in Philadelphia are similar to those in the comparison communities before and after the tax in terms of age, gender, income, and household size (Table 1); however, there were several differences by race and ethnicity. The percentages of respondents that are African-American are similar before the tax (56.1 and 58.8 percent in Philadelphia and comparison communities, respectively), but, because the sample in 2017 is a new cross-section of consumers, the gap increased after the tax (60.6 and 52.9 percent). In contrast, there is a fairly sizable gap between the percentage of respondents that are Hispanic before the tax (27.2 and 14.9 in Philadelphia and comparison areas, respectively), but the percentages are similar after the tax (18.4 and 19.5 percent). There is a similar pattern for the other race category, which is defined as those responding that they are a single race other than

\footnotetext{
${ }^{12}$ Note, consumers at Philadelphia stores were not asked how frequently they shopped at Philadelphia stores, and consumers at comparison stores were not asked how frequently they shopped outside of Philadelphia. Also, there were not enough non-Philadelphia residents shopping at Philadelphia stores to estimate the change in the frequency of shopping outside of the city for this group.
} 
African-American, white, or multiple races. Finally, both before and after the tax, the percentages of respondents who are white were substantially higher in comparison communities. We include all of these individual characteristics in the regressions for the analysis of purchases to account for differences across Philadelphia and the comparison communities and the pre- and post-tax periods.

Table 2 displays the mean amount of beverages purchased in ounces in 2016, before the tax, and in 2017, after the implementation of the tax, for residents of Philadelphia and the comparison communities. The average consumer in Philadelphia purchased 13.2 ounces of taxed beverages ( 8.5 ounces of regular or diet soda) and 7.4 ounces of untaxed beverages ( 4.2 ounces of bottled water) per shopping trip in 2016. After the tax was implemented in 2017, the average consumer in Philadelphia purchased 11.1 ounces of taxed beverages (6.9 ounces of regular or diet soda) and 10.4 ounces of untaxed beverages (5.5 ounces of bottled water) per shopping trip. The decrease in purchases of taxed beverages and increase in untaxed beverages over time within Philadelphia are not statistically significant, as shown in the third column. ${ }^{13}$

The average consumer in the comparison communities purchased less taxed beverages but a similar amount of untaxed beverages than Philadelphia consumers purchased in 2016. In the comparison communities, consumers purchased an average of 8.2 ounces of taxed beverages and 6.7 ounces of untaxed beverages per shopping trip before the implementation of the tax. After the tax was implemented in 2017, purchases among consumers in the comparison communities rose by 6.8 ounces to an average of 15.0 ounces per shopping trip for all taxed beverages and rose by 5.3 ounces to an average of 8.8 ounces per shopping trip for regular and diet soda. There were no statistically significant changes over time in purchases of untaxed beverages within the comparison communities. Primarily because of the increase in purchases outside of Philadelphia, the differences in average purchases over time in Philadelphia compared to the differences over the same time period in the comparison communities was a decrease of 8.9 ounces of all taxed beverages and 6.9 ounces of regular and diet soda per shopping trip.

An important identifying assumption of the DiD model is that, in the absence of the tax, the trend in outcomes in Philadelphia would be equal to the trends in the comparison communities. Comparison communities geographically close to the city of Philadelphia were chosen because they were more likely to share any unobserved shocks to the outcomes (such as

\footnotetext{
${ }^{13}$ We refer to statistically significant results as those with a p-value of 0.05 or less unless noted otherwise.
} 
effects of changes to the local economy or changes in television or radio advertising of SSBs). Even though the mean volume purchased varied at baseline (pre-tax), in the absence of crossborder shopping, the DiD approach will identify the relative changes due to the tax if the trends (not levels) of purchases for consumers interviewed in Philadelphia and the comparison communities were parallel and would have continued to be parallel in absence of the tax. We do not know the pre-tax trends in purchases at the stores in our sample, but from the Nielsen Retail Scanner Data (referred to as RMS data), we find supporting evidence that the trends in purchases were parallel for retailers in Philadelphia and the area outside of Philadelphia but in the Philadelphia MSA. ${ }^{14}$ As shown in Appendix Figure 1, the trends in the average weekly sales volume of regular soda, diet soda, and juice drinks were generally parallel in the year before the tax. ${ }^{15}$ In addition, by conducting interviews and enrolling households at stores in areas that were matched based on store type and population characteristics, we sought to minimize differences in purchases and consumption at baseline as well as differences in the population characteristics of Philadelphia and the comparison communities.

\section{$\underline{\text { Relative changes in purchases }}$}

Table 3 displays the regression-adjusted DiD estimates of the relative changes in beverage purchases in Philadelphia. The first column shows the estimates for all consumers for all beverages, all taxed beverages, regular and diet soda, all untaxed beverages, and bottled water. The volume of beverages purchased decreased by 6.0 ounces per shopping trip in Philadelphia relative to the comparison stores, but this estimate is not statistically significant. For all taxed beverages, which include SSBs and diet soda, the purchases decreased by 8.9 ounces per shopping trip. This estimate is nearly identical to the unadjusted comparisons of

\footnotetext{
${ }^{14}$ Using the RMS data, we examined the average weekly sales volume (in ounces) of regular soda, diet soda, and juice drinks for all retailers in Philadelphia and the Philadelphia MSA. Each retailer in the data set reported the weekly price and sales volume for every UPC code with any sales volume during the week. Based on the UPC code, Nielsen categorizes beverage types. Sports drinks, energy drinks, and sweetened teas are not defined separately in the data. The RMS data include the three-digit zip code and the FIPS county code of each store, so we were able to determine which retailers are located in the city of Philadelphia and in the Philadelphia MSA outside of Philadelphia. According to the RMS data, there were about 24,000 regular sodas, 18,000 diet sodas, and 19,000 juice drinks sold in retail stores in Philadelphia each week during 2016; and about 15,000 regular sodas, 9,000 diet sodas, and 11,000 juice drinks sold in retail stores in the Philadelphia MSA each week.

15 The conclusions drawn from the Nielsen data are those of the researchers and do not reflect the views of Nielsen. Nielsen is not responsible for, had no role in, and was not involved in analyzing and preparing the results reported herein.
} 
means shown in Table 2. For regular and diet soda, purchases decreased by 6.1 ounces, which is statistically significant at the 10 percent level and is very similar to the unadjusted estimate from Table 2. The estimate for purchases of untaxed beverages is positive, but not statistically significant.

The subsequent columns of Table 3 show estimates of the relative changes in beverage purchases by subgroup. Columns 2 and 3 display the estimates for African-American and Hispanic consumers. The estimates for purchases of all beverages and taxed beverages are negative, but not statistically significant. Column 4 shows that low-income consumers decreased their purchases by 12.7 ounces per shopping trip in Philadelphia stores compared to stores in the comparison areas.

Column 5 of Table 3 shows the estimates for Philadelphia residents. For all beverages, purchases decreased by 26.0 ounces per shopping trip at stores in Philadelphia relative to stores in the comparison areas, which is statistically significant at the 10 percent level. Purchases of taxed beverages decreased by 27.0 ounces. The estimates for Philadelphia residents could reflect a decrease in purchases at stores within Philadelphia and an increase in purchases at stores outside of Philadelphia. To better understand the roles of residence and shopping location, we next examine cross-border shopping.

\section{Cross-border shopping}

Table 4 displays estimates of changes in shopping behavior based on observations and responses from the exit interviews. The first estimate shows that there was not a statistically significant change in the percentage of consumers outside of Philadelphia who were Philadelphia residents. However, based on the estimate in the second row, we find that the percentage of Philadelphia residents shopping outside of Philadelphia who purchased a taxed beverage increased by 29 percentage points (compared to 16.8 percent at baseline). The estimate of the change in the volume of taxed beverages that those consumers purchased is large and positive (16.9 ounces per shopping trip) but not statistically significant (compared to 16.6 ounces at baseline). These results suggest that residents from Philadelphia were not more likely to travel outside of Philadelphia to shop as a result of the tax, but when they did travel outside of Philadelphia, they were more likely to purchase beverages that would be taxed in Philadelphia. 
The next set of results show that individuals' self-reported broader shopping patterns are consistent with cross-border shopping. The likelihood of self-reported shopping in Philadelphia at least once a week declined by 21 percentage points among both Philadelphia residents and non-Philadelphia residents interviewed at stores in the comparison communities. There was a slight increase in the likelihood of self-reported shopping outside of Philadelphia among Philadelphia residents interviewed at stores within Philadelphia, but the estimate is not statistically significant. ${ }^{16}$ Thus, the tax did not seem to change whether Philadelphia residents shopped outside of the city, but Philadelphia residents who already shopped outside of the city were more likely to continue doing so after the implementation of the tax. ${ }^{17}$

\section{Impacts on consumption}

\section{a. Methods}

We use the responses to the longitudinal household survey to estimate the impact of the tax on consumption among adults and children. Our main outcomes are monthly frequency of consumption of a variety of beverages, daily added sugar consumption from beverages, daily consumption of a variety of beverages, and any consumption of a variety of beverages. We regress the outcomes on treatment status (household lives in Philadelphia), the values of the outcome at baseline, and a set of covariates.

The general framework is analogous to the DiD framework discussed above; however, the approach estimates the impact of the tax on within-individual changes in consumption conditional on baseline consumption and the model covariates, which requires a different identifying assumption than DiD. For DiD, identification requires the assumption of parallel trends between the treatment and comparison groups in the absence of the tax. We, instead, use a method that controls for the lagged outcome (i.e., consumption before the tax) that requires the assumption of unconfoundedness conditional on the lagged outcome. In a panel setting, for

\footnotetext{
${ }^{16}$ There is also little change in the likelihood of self-reported shopping outside of Philadelphia among nonPhiladelphia residents interviewed at stores within Philadelphia, but this is a very small sample.

${ }^{17}$ Consistent with this conclusion, we find no change in the probability that Philadelphia households respond that they ever shop outside the city for beverages, but a 17 percentage point increase in the likelihood that their usual source of beverage purchases is outside of the city. We also find that, in the household survey following the tax, there was an increase in the number of minutes that adults reported it took them to travel to shop for beverages, but the estimate is not statistically significant. Additionally, household survey respondents in Philadelphia were 12 percentage points more likely to report that price was the primary factor in determining where they purchased beverages, but this estimate is only statistically significant at the 10 percent level.
} 
which we have an observation of pre-treatment outcome, and given that we observe differences in mean consumption levels between the treatment and comparison groups before the tax (discussed later in this section), this approach is preferred over a DiD approach (Imbens and Wooldridge, 2009).

We estimate the impact of the tax on continuous outcomes for adults and children. The outcomes include the monthly frequency of consumption of all taxed beverages and specific taxed beverages: regular soda, diet soda, and sweetened fruit drinks. ${ }^{18}$ The outcomes also include all untaxed beverages and specific untaxed beverages: coffee (adults only), milk, bottled water, and 100 percent juice. ${ }^{19}$ In addition, we examine the effects on the daily intake of added sugars from SSBs, in grams. To estimate the effects on these outcomes, we estimated regressions of the form:

$$
Y_{1 i}-Y_{0 i}=\beta_{0}+\beta_{1} \text { Phil }+\beta_{2} Y_{0 i}+\beta_{3} X_{i}+\epsilon_{i}
$$

where $Y_{1 i}-Y_{0 i}$ is the change in consumption between baseline data collection (pre-tax) and follow-up (post-tax) for person $i$. Phil is a binary variable equal to 1 if the respondent lives in Philadelphia and equal to 0 if the respondent lives in a comparison area. For the consumption analysis, we define this variable based on the location of the residence, as opposed to the location of the store for equation (1). $Y_{0 i}$ is the baseline consumption level reported by person $i . X_{i}$ is a vector of individual-level characteristics including age, race, gender, ethnicity, education level of the sample adult, and household income. $\beta_{1}$ is the coefficient of interest and represents the effect of the tax on consumption. We estimate the regression above using ordinary least squares (OLS) and cluster standard errors at the store level to account for correlations between observations within stores, which was how respondents for the survey were originally identified. ${ }^{20}$ All results

\footnotetext{
${ }^{18}$ We received a small number of implausible survey responses to the questions about monthly frequency of consumption. We removed records from the analysis that reported daily intake of any given individual beverage greater than 10 per day (or 300 per month). This approach is similar to the approach taken by NCI, in which they top code results for daily frequency at 7 or 8 per day depending on the beverage type.

${ }^{19}$ Most coffee drinks are untaxed. Any coffee drink sweetened by the consumer after the point of sale is untaxed. Sweetened coffee drinks are taxed unless they are at least 50 percent milk by volume. No product that is 50 percent milk by volume or greater is taxed, regardless of sweetener content. Most 100 percent juice is also untaxed; however, fruit juice concentrate is considered a sweetener in the Philadelphia tax legislation. If a fruit juice is made from concentrate, it is taxed if the final product is more concentrated than fresh juice of the same kind.

${ }^{20}$ The distributions for monthly frequency of consumption and grams of sugars consumed are right-skewed with a small number of extreme values, and there are a large number of observations at or near zero. Thus, we tested the
} 
are estimated using sample weights at the household level, which account for sample design, oversampling, and nonresponse. ${ }^{21}$

The impact of the tax on consumption may be heterogeneous, and estimates of the average impact of the tax on our sample may mask important differences across key baseline characteristics. To examine heterogeneity in the impact of the tax on consumption for adults and children, we estimate equation (2) interacting Phil with the following indicators: Hispanic ethnicity, African-American, household is below the FPL, member of household receives SNAP benefits, member of household receives WIC benefits, adult has greater than a high school education, adult never shops for beverages outside of Philadelphia at baseline, adult supports the tax at baseline, adult agrees that SSBs are bad for health at baseline, adult is trying to consume fewer SSBs at baseline, and child is over 10 years of age. We examine the impact of the tax by race, ethnicity, income, education, and public assistance to determine whether any of these key subgroups changed their consumption as a result of the tax. As we discussed in the introduction, these groups have higher rates of obesity and potentially different responses to the tax. We also examine the impact of the tax for those reporting that they do not shop outside of Philadelphia at baseline because cross-border shopping is one way that individuals can avoid the impact of the tax on their consumption of taxed beverages; thus, those not shopping for beverages outside of the city could be more likely to reduce consumption as a result of the tax. Similarly, those who supported the tax, who realized that SSBs are bad for their health, or who were trying to consume fewer SSBs might be more likely to reduce their consumption of taxed beverages. Finally, we are interested in whether older children, who were more likely to purchase beverages on their own (and many of whom directly responded to the survey), changed their consumption of taxed and untaxed beverages.

We also split the sample of Philadelphia households into two groups based on how far they lived from the border. We estimate the impact of the tax separately for respondents whose

sensitivity of the results to estimation of nonlinear regression techniques to address the non-normality of the outcomes (e.g., zero-inflated count models and two part models). The nonlinear models did not produce appreciably different estimates of the impacts of the tax compared to the results generate using OLS, and they did not result in improved precision. Moreover, the changes in the consumption outcomes, which are the primary outcomes, are approximately normally distributed; thus we report the estimates from the OLS regressions for the analysis of consumption.

${ }^{21}$ We impute missing values of all covariates using multiple imputation. Because all of the covariates aside from age (for which we use OLS) are binary or categorical, we use logistic regressions to impute missing values in the sample. We estimated all regressions with and without multiple imputation, and the impacts of using imputed values for the models' covariates were small. We report the results for the regressions using multiple imputation. 
address was in the top quartile by distance to the city border (in effect, those who lived in the middle of the city). Those living farther from the city border could have less opportunity to shop outside of the city at untaxed stores, and thus could be more likely to reduce their consumption of taxed beverages. Finally, we estimate the relationship between the impact of the tax and baseline consumption level. Individuals who consume greater amounts of taxed beverages could be more likely to reduce their consumption because they have more to gain in terms of health effects or simply because they have more room to improve; conversely, they could be less likely to improve if their consumption patterns are more ingrained. We estimate the relationships between baseline consumption and the impact of the tax by adding spline terms for baseline consumption with five knots to equation (2). We selected knots based on visual inspection of the distribution of baseline consumption for each outcome and to ensure that each spline term was supported by adequate numbers of observations.

We also estimate the impact of the tax on several binary outcomes, including any consumption of that beverage type during the month and daily consumption throughout the month. We use a framework similar to the framework we use for continuous outcomes, except that the outcome is a binary variable measured after the tax was implemented, instead of the change in the outcome over time. Thus, we regress the post-tax outcome on treatment status, baseline outcome, and a set of individual-level covariates (described above for equation 2). We use sample weights to account for the sampling design, and nonresponse and cluster standard errors at the store level to account for correlations between observations within stores, which was how respondents for the survey were originally identified.

\section{b. Results}

We report summary statistics for respondent characteristics separately for Philadelphia and the comparison communities in Table 5. The mean characteristics are very similar for the two groups. There are no statistically significant differences.

Table 6 presents the mean number of times beverages were consumed per month and the mean amount of added sugars consumed from beverages in each time period. Results for Philadelphia are in the left-hand columns, and results for the comparison communities are in the right-hand columns, with the unconditional DiD estimate in the farthest-right column. These statistics are presented for adults (top panel) and children (bottom panel). 
Among adults, monthly frequency of consumption of all taxed beverages decreased by 3.6 in Philadelphia and rose by 4.5 in the comparison communities. The unconditional DiD estimate is that monthly frequency of taxed beverage consumption fell by 8.1, although it is imprecisely estimated and not statistically significant. We examine the two most commonly consumed types of taxed beverages: soda and diet soda. For adults, the unconditional DiD estimate is that monthly frequency of soda consumption fell by 17.5 , which is statistically significant. The unconditional DiD estimate is that the change in monthly frequency of diet soda consumption is very small (-0.4) and not statistically significant. There are no statistically significant DiD estimates for untaxed beverages combined, or for bottled water or coffee, specifically. In the final row of the top panel, the unconditional DiD estimate is that, for adults, added sugars from beverages fell by 9.8 grams per day, which is statistically significant at the 10 percent level. For both of the two statistically significant changes among adults-frequency of soda consumption and added sugar consumption — the decreases result not only from reductions in Philadelphia, but also from increases in the comparison communities.

Results for children are shown in the bottom panel of Table 6. None of the unconditional DiD estimates are statistically significant for children. The DiD estimates for consumption of taxed beverages, soda, and added sugars are small. The reductions in untaxed beverages, bottled water, and milk are larger (reductions in monthly frequency of 10 or greater), but the estimates are imprecise.

Table 7 presents the estimates of the impact of the tax on consumption for the adult sample (left columns) and the child sample (right columns). For each sample, we report the results of two specifications: specification $\mathrm{A}$, which controls only for baseline consumption; and specification B, which also controls for gender, age, race, education, and household income.

The results indicate that monthly frequency of taxed beverage consumption did not change substantially in Philadelphia relative to the comparison communities after the tax. We estimate reductions of roughly 4 to 5 times for adults and of 2 to 4 times for children per month (compared to baseline frequencies of roughly 54 times per month for adults in Philadelphia and 38 times for children), but the estimates are not statistically significant. When examining specific categories of taxed beverages, we find there was a statistically significant reduction in the monthly frequency of soda consumption for adults (as there was in the unconditional estimates described earlier). Specifically, we estimate that the tax reduced the monthly frequency of adults' 
soda consumption by 10 to 11 (compared to baseline frequency of roughly 34 times per month). There are no statistically significant changes in children's consumption of specific categories of taxed beverages, and the point estimates are small and negative (typically below 1 fewer times per month, with a high of 2.4 fewer times per month for sweetened fruit drinks). There are also no statistically significant changes in the consumption of untaxed beverages, or of specific categories of untaxed beverages (bottled water, coffee, 100 percent fruit juice, or milk), for adults or children.

The final row of the table presents results for monthly consumption of added sugars (in grams per day). In our parsimonious specification, adults' daily sugar consumption falls by 7.7 grams, which is statistically significant at the 5 percent level. However, when we add to the specification controls for age, gender, race, education, and income, the estimate (a reduction of 5.9 grams) is less precisely estimated and not quite statistically significant at the 10 percent level. The estimates for children are smaller and not statistically significant.

We next examine other measures of consumption: first, whether the individual consumed any of that beverage in the past month (the extensive margin) and whether the individual consumed that beverage 30 or more times in the past month, which we refer to as daily consumption. ${ }^{22}$ Table 8 presents results for the regressions of any consumption and daily consumption that control for age, gender, race, education, and income. Results for adults (the left-hand columns) suggest that the tax reduced the probability of adults drinking any taxed beverage by 5.4 percentage points, compared to 94.8 percent of adults drinking any taxed beverage at baseline. Looking at specific categories of taxed beverages, the overall finding for taxed beverages seems to be driven by a large (16.7 percentage point) reduction in the probability of drinking diet soda, compared to 27.0 percent of adults drinking any diet soda at baseline. The tax is also associated with a relatively large (10.7 percentage points) and statistically significant increase in the probability of drinking $100 \%$ juice. For daily consumption, the only statistically significant result is that adults in Philadelphia were 12.0 percentage points less likely to consume soda daily after the tax relative to adults in the control communities. At baseline, 35.6 percent of adults reported daily consumption of regular soda.

\footnotetext{
${ }^{22}$ We acknowledge that one could consume a beverage 30 or more times in a month but not consume it daily; however, it is typical in this literature to define consumption that averages 1 or more per day as daily consumption (e.g., Zhong et al., 2018).
} 
The right-hand columns of Table 8 present results for children. There are no statistically significant estimates of the effect of the tax on the probability that children are consumers of any category of beverage or the probability that children are daily consumers of any beverage category. Moreover, the point estimates tend to be small.

To test for heterogeneous effects, we add to the specification an additional interaction that allows the impacts to vary by key subgroups (e.g., African-American and Hispanic adults and children) and potential mediating variables (e.g., distance from the households to the border, whether they shop for beverages outside of the city, and their views on SSBs). We present the impact estimates for these subgroups and potential mediating factors in Table 9 for two outcomes: grams of added sugars per day and monthly consumption of regular soda. Among African-American children, we find that the tax is associated with a decrease in grams of sugars consumed per day (8.0 grams). Among African-American adults, we find decreases in grams of sugar consumed (8.1 grams) and the monthly frequency of regular soda consumption (14.6 fewer times per month), although the former result is not quite statistically significant at the ten percent level. We did not observe statistically significant changes in consumption for Hispanic adults and children by poverty, public assistance, education or specifically for older children (over 10 years of age).

Regarding attitudes toward SSBs and the tax, we find statistically significant decreases in consumption among adults that responded that SSBs are bad for their health. We find reductions in consumption for adults that responded they were trying to reduce SSB consumption, although the decreases are not precisely estimated; and we did not find statistically significant changes for adults that support the tax. Surprisingly, we find mixed results for adults and children by distance between the household and the Philadelphia border (adults living far from the border reduced consumption but children living far from the border increased consumption). There were no statistically significant changes in consumption for adults responding that they did not shop for beverages outside of Philadelphia.

Finally, we test for heterogeneity in the impact of the tax on daily consumption of added sugars from SSBs (in grams) by baseline consumption level for adults and children. We find that survey respondents who report high consumption of added sugars at baseline experienced larger impacts of the tax on consumption. This relationship is not always monotonic, and, because the 
distribution of self-reported consumption is highly skewed, estimated impacts of the tax at higher baseline consumption levels are often imprecise.

Figures 1 and 2 show the impact of the tax on the individual changes in grams of added sugars consumed per day plotted against grams of added sugars consumed per day before the implementation of the tax. Figure 1 indicates that adults who consumed more added sugars before the tax reported a larger decrease in added sugars consumption than adults who reported low levels of consumption before the tax, although the relationship is not precisely estimated for all levels of baseline consumption. Figure 2 indicates that children with high consumption of added sugars before the tax reported a larger decrease in the consumption of added sugars than children with low consumption before the tax. The reductions in consumption are large and statistically significant for children with high baseline consumption. For example, children who, before the tax, consumed 67 grams of sugar per day on average (which is approximately one 20 ounce bottle of regular soda) reduced their consumption by roughly 15 grams or 22 percent. Appendix Figures 2 and 3 show that the changes in added sugars are reflected in the patterns of changes in the frequency of consuming regular soda based on baseline consumption levels. Most notably, children with high levels of regular soda consumption before the tax reduced their consumption after the tax.

\section{Discussion}

Since 2015, numerous cities in the U.S. and countries around the world have enacted taxes on sugar-sweetened beverages. This paper contributes to the literature on the impact of these taxes by providing the first estimates of the impact on children's consumption and the most comprehensive evidence of the impact of the beverage tax in Philadelphia.

Overall, we find that the estimates of the impact of the tax on the consumption of added sugars from SSBs and the frequency of consuming all taxed beverages are negative but not statistically significant for children and adults. Additionally, the point estimates are modest in size. For children, the estimate for added sugars is a decrease of 2.4 grams per day, which is a decrease of 12.5 percent. A gram of added sugars is 4 calories, so this estimate implies a decrease of only 9.6 calories per day or roughly 0.6 percent of the daily recommended caloric 
intake. ${ }^{23}$ For adults, the estimate of a decrease of 5.9 grams of added sugars per day translates to a reduction of 23.6 calories per day or roughly 1.2 percent of the recommended 2,000 calories per day; this estimate is not statistically significant once we control for demographic and socioeconomic characteristics. To illustrate the magnitude of the point estimate, Hall et al. (2011) estimate that a sustained reduction in consumption of 10 calories per day leads to an eventual weight loss of 1 pound, with roughly half of the weight loss occurring after one year. Thus, the estimated reduction of 23.6 calories per day by adults implies a long-term reduction of slightly more than 2 pounds. The estimates for changes in the frequency of consumption for all types of beverages are modest in size and not statistically significant for children. The point estimate for regular soda is -0.2 or less than 1 percent.

On the other hand, we find that, due to the tax, adults in Philadelphia consumed regular soda 10.4 fewer times per month, which is a reduction of approximately 30 percent. Put another way, adults in Philadelphia consumed approximately one regular soda per day before the tax, and the tax reduced consumption by roughly one soda every three days. The tax reduced adults' probability of consuming regular soda daily by 11.1 percentage points or approximately 31 percent.

We compare our estimates for adult consumption to the only previous paper on the impact of the Philadelphia tax. Zhong et al. (2018) estimated the impact of the Philadelphia tax using two repeated cross-sections of phone surveys of adults shortly before and 1-2 months after the tax. They find that the probability of daily consumption of soda by adults fell 40 percent, and the monthly frequency of soda consumption by adults fell 38 percent. They also estimate that the probability of daily consumption of bottled water by adults rose 58 percent. Their estimates for the probability of daily consumption or the frequency of consumption for other beverage types are not statistically significant. Our measures of consumption are constructed from similar survey questions. In contrast, our data are longitudinal, and our post-tax data are 10-11 months after the tax was implemented. However, we find similar estimates to Zhong et al. (2018) for the consumption of regular soda. We find that the tax reduces the probability that an adult consumes regular soda daily by approximately 31 percent and the monthly frequency of regular soda

\footnotetext{
${ }^{23}$ The average age of children in our sample is 8 years old. The National Institutes of Health (NIH) estimates that "somewhat active" children aged 4-8 years require 1,400 to 1,600 calories per day (NIH, 2018). Using the upper end of that range because of the age of children in our sample $(1,600)$, the decrease in consumption of 9.6 calories per day represents roughly 0.6 percent of the recommended intake.
} 
consumption by 30 percent. We do not find a statistically significant change in daily consumption of bottled water. In Philadelphia, daily consumption of bottled water was high prior to the tax at 66.7 percent, and the point estimates imply that the probability that adults consume bottled water daily rose 6.2 percentage points, or 10.0 percent. There are no previous studies of the impact of SSB taxes in U.S. cities to compare our estimates for the consumption of children.

We also examine heterogeneity in the effects of the tax. African-American adults and children reduced their consumption of added sugars from SSBs, and adults that agreed that SSBs are unhealthy reduced their consumption of sugar and frequency of consuming regular soda. For African-American children, the reduction of added sugars by 8.0 grams per day translates to a decrease of 32 calories per day. This estimate is larger than the overall estimate for all children and suggests that the tax reduces consumption for demographic groups with high levels of SSB consumption and the greatest risk for becoming obese. For African-American adults, the tax reduces the frequency of regular soda consumption by 14.6 times per month or nearly one fewer soda every other day. We did not find precisely estimated effects of the tax by poverty level, participation in SNAP or WIC, or education. We also did not find consistent evidence that adults and children that live farther from the city border in Philadelphia or households that never shop for beverages outside of Philadelphia substantially reduced their consumption.

The estimates for consumption among children are often small and not statistically significant, except for African-American children. These results could be influenced by the average age of children in the sample (roughly 8 years old) and the low baseline levels of consumption among children in Philadelphia (19.1 grams of added sugars daily and 16.1 regular sodas per month). We find negative point estimates for the consumption of added sugars and frequency of consumption of regular soda among older children in the sample, although the estimates are not precisely estimated. On the other hand, we find that the tax had an effect for children with high baseline consumption, with statistically significant reductions in consumption for children who consumed at least 67 grams of added sugars per day prior to the tax. Thus, for children in the far right tail, at least the 93rd percentile, of the baseline consumption distribution, the tax meaningfully decreases consumption. The tax decreased the consumption of added sugars by 22 percent for children for children who consumed 67 grams of added sugars at baseline, which is approximately a complete 20-ounce bottle of regular soda, and the size of the 
effect increases for children with higher baseline consumption levels. These decreases in added sugars are driven by decreases in the frequency of consuming regular soda. Thus, we find evidence of a fairly sizable effect of the tax for children who were consuming high levels of SSBs before implementation of the tax who are likely those at the greatest risk of health complications from SSB consumption.

Further, this paper provides the only estimates of Philadelphia's beverage tax on purchases and cross-border shopping. We find that the average amount of taxed beverages purchased per shopping trip decreased in Philadelphia and increased in comparison communities, which results in a relative decrease of 8.9 ounces per shopping trip at stores in Philadelphia. Assuming an average of 16 trips per month (Ver Ploeg, Larimore, and Wilde, 2017), the tax decreased purchases of all taxed beverages by 142.4 ounces, or slightly more than two 2-liter bottles, per month by consumers in stores in Philadelphia relative to consumers in stores in the comparison areas. We find that this estimate for purchases is, at least partially, influenced by cross-border shopping. Philadelphia residents shopping at stores outside of the city were more likely to purchase taxed beverages and purchased more taxed beverages on average after the tax. In addition, consumers interviewed at stores outside of Philadelphia were much less likely to respond that they regularly shop for beverages at stores in Philadelphia after the implementation of the tax, and those interviewed at stores in Philadelphia were slightly more likely to respond that they regularly shop for beverages outside of the city. Finally, these findings are supported by responses to the household survey; we find that households are more likely to respond that their usual source of beverage purchases is outside of the city and that price was the primary factor in determining where they shop. Consistent with this finding, Cawley et al. (2018) find that the Philadelphia tax was fully passed through to consumers in the form of higher prices, which provides an incentive for Philadelphia residents to shop outside of the city.

The evidence of cross-border shopping in response to the tax provides a plausible explanation for the modest effects we find on the consumption of beverages. Consumers appear to shift some portion of their beverage purchases to stores outside of city, which is consistent with the literature on cross-border shopping to avoid taxes on food (Tosun \& Skidmore, 2007). Furthermore, shopping outside of Philadelphia seems plausible for many of the city's residents; the average store in our sample in Philadelphia was 3.2 miles away from the closest untaxed store outside of the city, and 27.6 percent of Philadelphia residents interviewed at Philadelphia 
stores reported shopping outside of the city one or more times per week. This finding has important ramifications for the potential differential effects on households that do not have the ability to cross the border regularly to shop for beverages. It is possible that the tax is less effective for these households, dampening any possible reductions in SSBs and potentially increasing their expenditures on beverages relative to others than shop outside of the city. Interestingly, we find slightly larger relative declines in purchases of taxed beverages for households living below the FPL, suggesting greater cross-border shopping. We do not find substantial reductions in reported consumption for low-income groups nor for those living farther from the city border.

This study has the following limitations. We have a small number of clusters, with only two time periods and a comparison of Philadelphia to comparison communities in the same MSA; past studies of city-level beverage taxes have all had a limited number of clusters (e.g., Cawley and Frisvold, 2017). This study, like past studies of the tax in Berkeley, CA (Falbe et al., 2015; Cawley and Frisvold, 2017), uses comparison communities that are close to the treated community. Advantages of this approach are that the nearby comparison communities are likely to share any regional shocks experienced by the treated community and the control communities (in the same media market) are exposed to the same information about SSBs that is disseminated during debates over whether to introduce a beverage tax. A disadvantage is that the tax may have spillover effects on the outcomes outside of the city. In addition, although the analysis of purchases using exit interviews from stores enables us to study cross-border shopping, this method does not provide estimates of how the tax affected households' beverages purchases. A direction for future research is to compare our results for purchases using exit interviews to estimates of household-level impacts on purchases from scanner data; scanner data typically contain household purchases and cannot provide information on the impact of the tax on consumption. Further, when examining the effects of the tax for multiple subgroups of adults and children and two outcomes, it is possible that we find precisely estimated impacts for some results simply due to chance. To address this concern, we construct a summary measure of beverage consumption (added sugars) and assess whether the results for a subgroup are consistent for multiple outcomes and whether similar subgroups (for example, the household is below the FPL and receives SNAP benefits) show similar results. Finally, our survey data are self-reported, which may contain some degree of reporting error. To the extent the tax affected 
the extent of reporting error in Philadelphia relative to the nearby comparison communities, such a change may bias our estimates of the impact of the tax on consumption.

Despite these limitations, this paper provides the only existing evidence on the impact of SSB taxes on the consumption of children, in addition to adults, and provides comprehensive information about the effects of a beverage tax in the largest U.S. city with a tax. 


\section{References}

Cawley, J., \& Frisvold, D. E. (2017). The Pass-Through of Taxes on Sugar-Sweetened Beverages to Retail Prices: The Case of Berkeley, California. Journal of Policy Analysis and Management, 36(2), 303-326.

Cawley, J., Frisvold, D.E., Hill, A., \& Jones, D.J. (2018a). The Impact of the Philadelphia Beverage Tax on Prices and Product Availability. (Working paper).

Cawley, J., Willage, B., \& Frisvold, D. (2018b). Pass-Through of a Tax on Sugar-Sweetened Beverages at the Philadelphia International Airport. Journal of the American Medical Association, 319(3), 305-306.

Donald, S. G., \& Lang, K. (2007). Inference with Difference-in-Differences and Other Panel Data. Review of Economics and Statistics, 89, 221-233.

Dubois, P., Griffith, R., \& O’Connell, M. (2017). How Well Targeted Are Soda Taxes? (Working paper).

Falbe, J., Thompson, H.R., Becker, C.M., Rojas, N., McCulloch, C.E., \& Madsen, K.A. (2016). Impact of the Berkeley Excise Tax on Sugar-Sweetened Beverage Consumption. American Journal of Public Health, 106(10), 1865-1871.

Fletcher, J.M., Frisvold, D.E., \& Tefft, N. (2010). The Effects of Soft Drink Taxes on Child and Adolescent Consumption and Weight Outcomes. Journal of Public Economics, 94, 967-974.

Fletcher, J.M., Frisvold, D.E., \& Tefft, N. (2015). Non-Linear Effects of Soda Taxes on Consumption and Weight Outcomes. Health Economics, 24(5), 566-582.

Fryar, C.D., Carroll, M.D., \& Ogden, C.L. (2016). Prevalence of Overweight, Obesity, and Extreme Obesity Among Adults Aged 20 and Over: United States, 1960-1962 Through 2013-2014. National Center for Health Statistics Health E-Stats. July.

Fryar, C.D., Carroll, M.D., \& Ogden, C.L. (2016b). Prevalence of Overweight and Obesity Among Children and Adolescents Aged 2-19 Years: United States, 1963-1965 Through 2013-2014. National Center for Health Statistics Health E-Stats. July.

Hall, K.D., Sacks, G., Chandramohan, D., Chow, C.C., Wang, Y.C., Gortmaker, S.L., \& Swinburn, B.A. (2011). Quantification of the Effect of Energy Imbalance on Bodyweight. Lancet, 378(9793), 836-837.

Hales C., Carroll M., Fryar C., Ogden C. (2017). Prevalence of obesity among adults and youth: United States, 2015-2016. NCHS data brief, no 288. Hyattsville, MD: National Center for Health Statistics.

Imbens, G.W., \&. Wooldridge, J. M. (2009). Recent Developments in the Econometrics of Program Evaluation. Journal of Economic Literature, 47(1), 5-86.

Malik, V.S., \& Hu, F.B. (2011). Sugar-Sweetened Beverages and Health: Where Does the Evidence Stand? American Journal of Clinical Nutrition, 94, 1161-1162. 
National Cancer Institute. Dietary Screener Questionnaire (DSQ) in the NHANES 2009-10:

Data Processing \& Scoring Procedures. Retrieved from https://epi.grants.cancer.gov/nhanes/dietscreen/scoring.

National Institutes of Health. (2018). Parent Tips: Calories Needed Each Day. Retrieved from https://www.nhlbi.nih.gov/health/educational/wecan/downloads/calreqtips.pdf.

NCD Risk Factor Collaboration. (2016a). Trends in Adult Body-Mass Index in 200 Countries from 1975 to 2014: A Pooled Analysis of 1,698 Population-Based Measurement Studies with 19.2 Million Participants. The Lancet, 387(10026), 1377-1396.

NCD Risk Factor Collaboration. (2016b). Worldwide Trends in Diabetes since 1980: A Pooled Analysis of 751 Population-Based Studies with 4.4 Million Participants. The Lancet, 387(10027), 1513-1530.

Powell, L.M., Chriqui, J.F., Khan, T., Wada, R., \& Chaloupka, J.F. (2013). Assessing the Potential Effectiveness of Food and Beverage Taxes and Subsidies for Improving Public Health: A Systematic Review of Prices, Demand and Body Weight Outcomes. Obesity Reviews, 14, 10-128.

Thow, A.M., Downs, S.M., Mayes, C., Trevena, H., Waqanivalu, T., \& Cawley, J. (2018). Fiscal Policy to Improve Diets and Prevent Noncommunicable Diseases: From Recommendations to Action. Bulletin of the World Health Organization, 96, 201-210.

Tosun, M. S., \& Skidmore, M. L. (2007). Cross-Border Shopping and the Sales Tax: An Examination of Food Purchases in West Virginia. The B.E. Journal of Economic Analysis \& Policy, 7(1), Article 63.

Ver Ploeg, Michele, Elizabeth Larimore, and Parke Wilde. (2017). The Influence of Foodstore Access on Grocery Shopping and Food Spending, EIB-180, U.S. Department of Agriculture, Economic Research Service, October 2017.

World Health Organization. Report of the Commission on Ending Childhood Obesity. (2016). Geneva: World Health Organization.

Zhong, Y., Auchincloss, A.H., Lee, B.K., \& Kanter, G.P. (2018). The Short-Term Impacts of the Philadelphia Beverage Tax on Beverage Consumption. American Journal of Preventive Medicine, 55(1), 26-34. 
Table 1. Characteristics of Exit Interview Respondents

\begin{tabular}{|c|c|c|c|c|c|c|}
\hline & \multicolumn{3}{|c|}{ Philadelphia } & \multicolumn{3}{|c|}{ Comparison Communities } \\
\hline & 2016 & 2017 & Difference & 2016 & 2017 & Difference \\
\hline \multirow[t]{2}{*}{ Age } & 39.973 & 39.673 & -0.301 & 38.315 & 38.892 & 0.577 \\
\hline & $(0.732)$ & $(0.603)$ & $(0.948)$ & $(0.613)$ & $(0.624)$ & $(0.875)$ \\
\hline \multirow[t]{2}{*}{ Female } & 53.919 & 60.026 & 6.106 & 55.831 & 56.738 & 0.907 \\
\hline & (3.197) & $(2.332)$ & (3.955) & $(2.927)$ & $(2.496)$ & $(3.846)$ \\
\hline \multirow[t]{2}{*}{ Hispanic } & 27.231 & 18.432 & -8.8 & 14.933 & 19.374 & 4.441 \\
\hline & (2.939) & $(1.650)$ & (3.369) & (1.889) & $(1.931)$ & $(2.700)$ \\
\hline \multirow{2}{*}{$\begin{array}{l}\text { African- } \\
\text { American }\end{array}$} & 56.111 & 60.599 & 4.488 & 58.812 & 52.886 & -5.926 \\
\hline & (3.199) & $(2.306)$ & $(3.942)$ & $(2.750)$ & $(2.527)$ & (3.733) \\
\hline \multirow[t]{2}{*}{ White } & 15.447 & 17.27 & 1.822 & 22.830 & 25.970 & 3.141 \\
\hline & $(2.288)$ & $(1.786)$ & $(2.901)$ & $(2.227)$ & (2.203) & (3.132) \\
\hline \multirow{2}{*}{$\begin{array}{l}\text { Other Race or } \\
\text { Multi-Racial }\end{array}$} & 28.442 & 22.131 & -6.311 & 18.359 & 21.144 & 2.785 \\
\hline & (2.903) & (1.910) & (3.474) & (1.962) & $(2.036)$ & $(2.827)$ \\
\hline \multirow{2}{*}{$\begin{array}{l}\text { Household } \\
\text { Size }\end{array}$} & 4.195 & 4.267 & 0.072 & 4.496 & 4.399 & -0.097 \\
\hline & (0.107) & $(0.083)$ & $(0.135)$ & $(0.093)$ & $(0.078)$ & $(0.121)$ \\
\hline \multirow[t]{2}{*}{ Below FPL } & 28.946 & 27.599 & -1.347 & 29.276 & 28.437 & -0.839 \\
\hline & (2.898) & $(2.202)$ & (3.638) & $(2.455)$ & $(2.341)$ & (3.391) \\
\hline Observations & 600 & 763 & 1,363 & 705 & 738 & 1,443 \\
\hline
\end{tabular}

Notes: The figures represent the mean characteristics of the exit survey respondents at Philadelphia stores and stores in comparison communities prior to the tax (2016) and after implementation of the tax (2017). Standard errors are in parentheses. 
Table 2. Beverage Purchases (Ounces) Before and After the Implementation of the Beverage Tax in Philadelphia

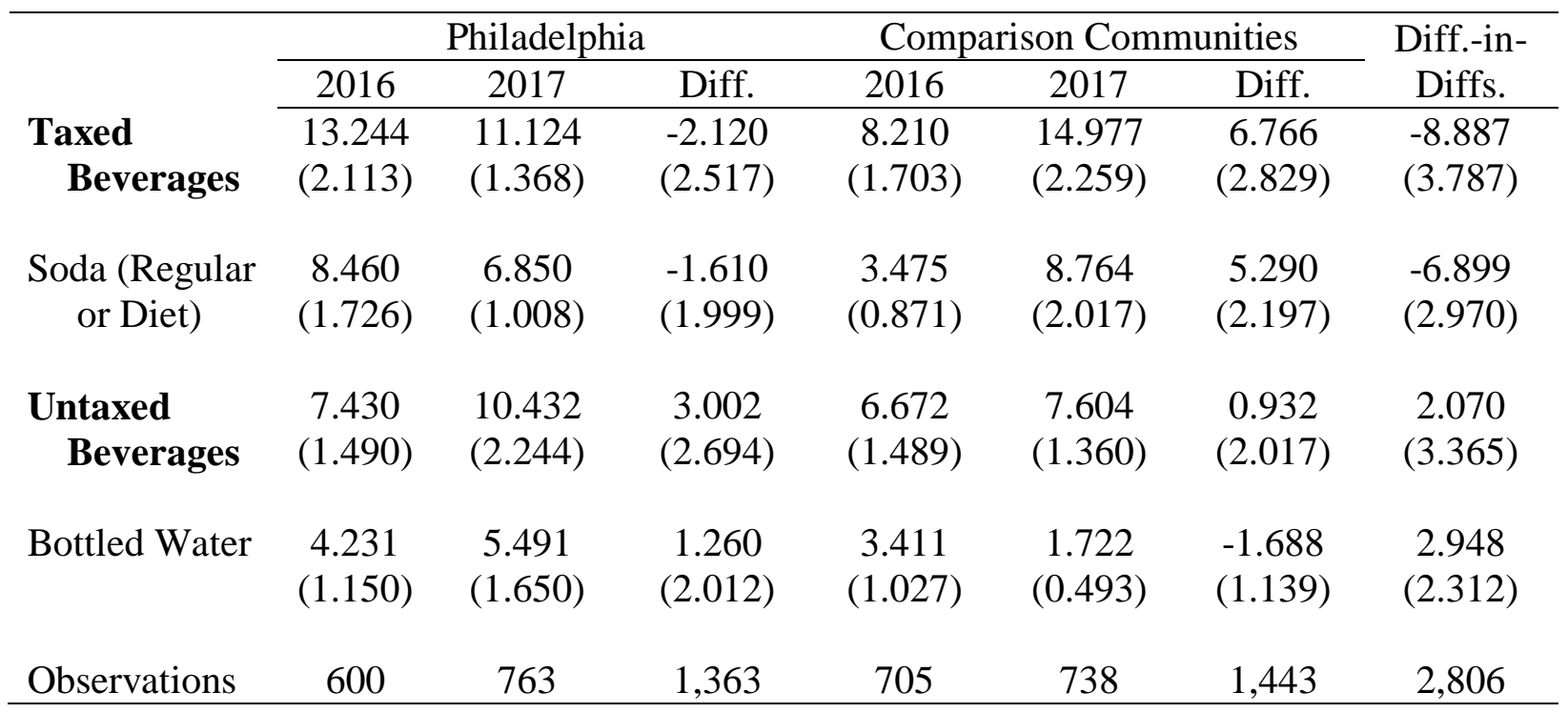

Notes: This table shows the mean ounces purchased among all beverages for the listed categories. Standard errors are in parentheses. Taxed Beverages include regular soda, diet soda, sports drinks, energy drinks, juice drinks (which contain less than 50 percent juice), and sweetened tea. Untaxed beverages include bottled water and 100 percent juice. 
Table 3. Relative Changes in Beverage Purchases (Ounces), Difference-in-Differences Estimates

\begin{tabular}{|c|c|c|c|c|c|}
\hline & Full Sample & $\begin{array}{l}\text { African- } \\
\text { American }\end{array}$ & Hispanic & Below FPL & $\begin{array}{l}\text { Philadelphia } \\
\text { Resident }\end{array}$ \\
\hline All Beverages & $\begin{array}{c}-6.045 \\
(5.737) \\
{[2,546]}\end{array}$ & $\begin{array}{c}-4.718 \\
(7.086) \\
{[2,546]}\end{array}$ & $\begin{array}{c}-6.810 \\
(12.418) \\
{[2,546]}\end{array}$ & $\begin{array}{c}-6.683 \\
(10.081) \\
{[2,546]}\end{array}$ & $\begin{array}{c}-26.855 \\
(14.140) \\
{[2,546]}\end{array}$ \\
\hline $\begin{array}{l}\text { All Taxed } \\
\text { Beverages }\end{array}$ & $\begin{array}{l}-8.863 \\
(4.301) \\
{[2,457]}\end{array}$ & $\begin{array}{l}-4.755 \\
(5.446) \\
{[2,457]}\end{array}$ & $\begin{array}{c}-4.525 \\
(6.659) \\
{[2,457]}\end{array}$ & $\begin{array}{l}-12.681 \\
(6.050) \\
{[2,457]}\end{array}$ & $\begin{array}{c}-27.022 \\
(13.420) \\
{[2,457]}\end{array}$ \\
\hline $\begin{array}{l}\text { Soda (Regular } \\
\text { and Diet) }\end{array}$ & $\begin{array}{l}-6.149 \\
(3.448) \\
{[2,563]}\end{array}$ & $\begin{array}{l}-4.230 \\
(3.964) \\
{[2,563]}\end{array}$ & $\begin{array}{c}0.130 \\
(5.037) \\
{[2,563]}\end{array}$ & $\begin{array}{l}-7.919 \\
(5.132) \\
{[2,563]}\end{array}$ & $\begin{array}{c}-16.130 \\
(13.886) \\
{[2,563]}\end{array}$ \\
\hline $\begin{array}{l}\text { Untaxed } \\
\text { Beverages }\end{array}$ & $\begin{array}{c}3.257 \\
(4.150) \\
{[2,466]}\end{array}$ & $\begin{array}{c}0.479 \\
(4.922) \\
{[2,466]}\end{array}$ & $\begin{array}{c}-0.233 \\
(10.924) \\
{[2,466]}\end{array}$ & $\begin{array}{c}8.102 \\
(7.056) \\
{[2,466]}\end{array}$ & $\begin{array}{c}4.248 \\
(4.993) \\
{[2,466]}\end{array}$ \\
\hline Bottled Water & $\begin{array}{c}2.539 \\
(2.339) \\
{[2,562]}\end{array}$ & $\begin{array}{c}5.089 \\
(3.458) \\
{[2,562]}\end{array}$ & $\begin{array}{c}2.728 \\
(7.120) \\
{[2,562]}\end{array}$ & $\begin{array}{c}2.474 \\
(3.621) \\
{[2,562]}\end{array}$ & $\begin{array}{c}1.476 \\
(4.441) \\
{[2,562]}\end{array}$ \\
\hline
\end{tabular}

Notes: This table shows the difference-in-differences estimates for the product category in the row heading and the sample in the column heading. Standard errors, which are robust to clustering at the store level, are in parentheses, and sample sizes are in brackets. Each cell contains the results of separate regressions. Additional variables that are included, but not shown, are age, gender (indicator for female), whether the respondent is African-American, whether the respondent is Hispanic, household size, whether household income is below the FPL, whether the respondent is a Philadelphia resident, indicators for days of the week, whether the interview location is in Philadelphia, whether the interview occurred after implementation of the tax, and store-type indicators. 
Table 4. Cross-Border Shopping

\begin{tabular}{lc}
\hline Observed Cross-Border Shopping & \\
\hline $\begin{array}{l}\text { Percentage of consumers outside Philadelphia who are } \\
\text { Philadelphia residents }\end{array}$ & 0.023 \\
& {$[0.025)$} \\
& {$[1,354]$} \\
Percentage of Philadelphia residents shopping outside & 0.289 \\
Philadelphia who purchase a taxed beverage & $(0.056)$ \\
& {$[198]$} \\
& \\
& 16.898 \\
Volume of taxed beverages purchased by Philadelphia & $(11.875)$ \\
residents shopping outside Philadelphia (ounces) & {$[198]$} \\
& \\
Self-Reported Cross Border Shopping & -0.206 \\
\hline $\begin{array}{l}\text { Interviewed at comparison store-Philadelphia residents } \\
\text { (reported shopping in Philadelphia }\end{array}$ & $(0.068)$ \\
one or more times per week) & {$[190]$} \\
& \\
Interviewed at comparison store-Non-Philadelphia residents & -0.207 \\
(reported shopping in Philadelphia & $(0.040)$ \\
one or more times per week) & {$[1,088]$} \\
Interviewed at Philadelphia store-Philadelphia residents & \\
(reported shopping outside Philadelphia & 0.043 \\
one or more times per week) & $(0.032)$ \\
\hline
\end{tabular}

Notes: Standard errors, which are robust to clustering at the store level, are in parentheses, and sample sizes are in brackets. Each cell contains the results of separate regressions. Additional variables that are included, but not shown, are age, gender (indicator for female), whether the respondent is African-American, whether the respondent is Hispanic, household size, whether household income is below FPL, indicators for days of the week, whether the interview occurred after implementation of the tax, and store-type indicators. 
Table 5. Characteristics of Household Survey Respondents

\begin{tabular}{lccc}
\hline & & Comparison & \\
& Philadelphia & Communities & Difference \\
\hline Age (adult) & 39.583 & 37.856 & 1.727 \\
& $(1.023)$ & $(1.237)$ & $(1.605)$ \\
Age (child) & 8.136 & 7.900 & 0.236 \\
& $(0.435)$ & $(0.439)$ & $(0.618)$ \\
Female (adult) & 0.662 & 0.609 & 0.053 \\
& $(0.047)$ & $(0.051)$ & $(0.069)$ \\
Female (child) & 0.502 & 0.568 & -0.066 \\
& $(0.048)$ & $(0.049)$ & $(0.068)$ \\
Hispanic & 0.240 & 0.182 & 0.058 \\
& $(0.041)$ & $(0.039)$ & $(0.057)$ \\
African-American & 0.659 & 0.632 & 0.027 \\
& $(0.044)$ & $(0.047)$ & $(0.065)$ \\
White & 0.178 & 0.242 & -0.064 \\
& $(0.034)$ & $(0.042)$ & $(0.054)$ \\
Other Race & 0.163 & 0.126 & 0.037 \\
& $(0.035)$ & $(0.030)$ & $(0.046)$ \\
Household Size & 4.277 & 4.609 & -0.332 \\
& $(0.179)$ & $(0.197)$ & $(0.266)$ \\
Household income below & & & \\
poverty level & 0.613 & 0.539 & 0.074 \\
& $(0.046)$ & $(0.052)$ & $(0.069)$ \\
High School Graduate & 0.480 & 0.468 & 0.012 \\
& $(0.048)$ & $(0.050)$ & $(0.069)$ \\
SNAP Recipient & 0.555 & 0.453 & 0.102 \\
& $(0.048)$ & $(0.050)$ & $(0.069)$ \\
WIC Recipient & 0.159 & 0.200 & -0.042 \\
& $(0.036)$ & $(0.041)$ & $(0.055)$ \\
Free or Reduced-Price Lunch & 0.320 & 0.422 & -0.102 \\
Recipient & $(0.043)$ & $(0.049)$ & $(0.065)$ \\
& & & \\
Observations & 241 & 199 & 440 \\
\hline
\end{tabular}

Notes: This table shows the mean characteristics of adults and children living in Philadelphia and in the comparison communities who responded to both waves of the household survey and the differences between the two groups. Standard errors are in parentheses. 
Table 6. Mean Consumption Before and After Implementation of the Beverage Tax in Philadelphia

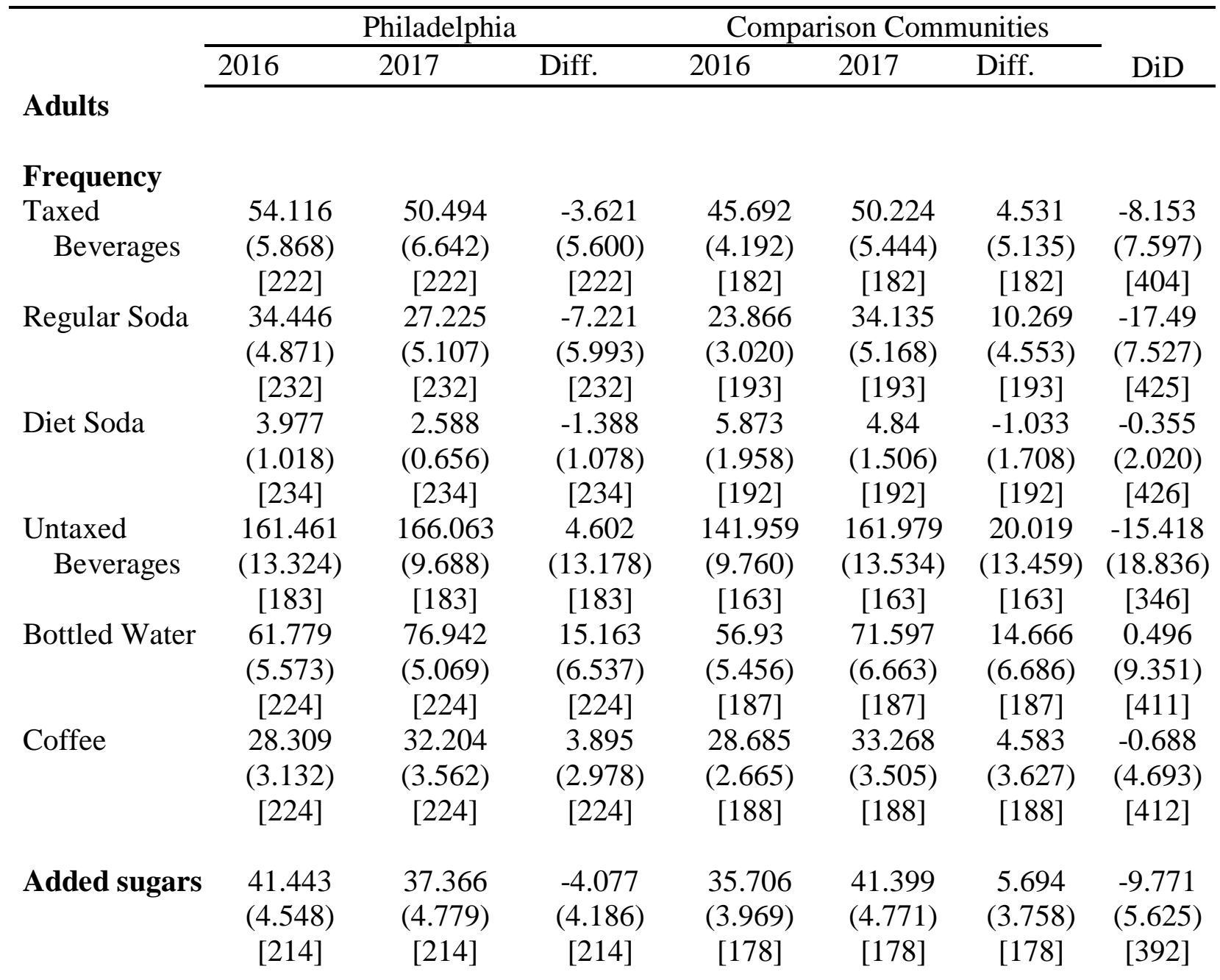

\section{Children}

$\begin{array}{lccccccc}\text { Frequency } & & & & & & \\ \text { Taxed } & 37.74 & 33.191 & -4.55 & 42.737 & 37.8 & -4.937 & 0.388 \\ \quad \text { Beverages } & (5.704) & (4.231) & (6.074) & (5.583) & (5.861) & (4.112) & (7.336) \\ & {[200]} & {[200]} & {[200]} & {[171]} & {[171]} & {[171]} & {[371]} \\ \text { Regular Soda } & 16.071 & 11.977 & -4.094 & 16.415 & 11.81 & -4.605 & 0.511 \\ & (3.828) & (2.124) & (4.151) & (2.585) & (2.107) & (2.122) & (4.662) \\ \text { Sweetened } & {[215]} & {[215]} & {[215]} & {[183]} & {[183]} & {[183]} & {[398]} \\ \text { Fruit drinks } & 21.803 & 19.693 & -2.11 & 21.761 & 20.803 & -0.959 & -1.151 \\ & (3.091) & (2.590) & (3.989) & (3.022) & (3.655) & (3.639) & (5.400) \\ \text { Untaxed } & {[211]} & {[211]} & {[211]} & {[176]} & {[176]} & {[176]} & {[387]} \\ \quad \text { Beverages } & 173.067 & 172.095 & -0.972 & 154.327 & 173.504 & 19.176 & -20.148 \\ & (12.257) & (10.518) & (11.295) & (10.135) & (16.162) & (15.184) & (18.922) \\ & {[180]} & {[180]} & {[180]} & {[153]} & {[153]} & {[153]} & {[333]}\end{array}$




\begin{tabular}{lccccccc} 
Bottled water & 55.725 & 57.52 & 1.796 & 41.842 & 55.641 & 13.799 & -12.003 \\
& $(6.134)$ & $(4.819)$ & $(6.893)$ & $(4.305)$ & $(7.639)$ & $(8.391)$ & $(10.858)$ \\
\multirow{4}{*}{ Milk } & {$[210]$} & {$[210]$} & {$[210]$} & {$[176]$} & {$[176]$} & {$[176$} & {$[386$} \\
& 62.097 & 54.592 & -7.505 & 51.481 & 54.244 & 2.763 & -10.268 \\
& $(5.646)$ & $(5.016)$ & $(5.152)$ & $(4.168)$ & $(6.981)$ & $(7.013)$ & $(8.702)$ \\
\multirow{4}{*}{ Added Sugars } & {$[207]$} & {$[207]$} & {$[207]$} & {$[175]$} & {$[175]$} & {$[175]$} & {$[382]$} \\
& 19.066 & 16.866 & -2.2 & 21.396 & 19.797 & -1.6 & -0.6 \\
& $(3.238)$ & $(2.187)$ & $(3.215)$ & $(2.833)$ & $(3.081)$ & $(2.704)$ & $(4.201)$ \\
& {$[189]$} & {$[189]$} & {$[189]$} & {$[170]$} & {$[170]$} & {$[170]$} & {$[359]$} \\
\hline
\end{tabular}

Notes: The figures are the unconditional mean values for the outcome variables (frequency of consumption by beverage type and added sugars) for adults and children by time and location. Standard errors are in parentheses. Sample sizes are in brackets. Beverages are in mean ounces and added sugars are in grams.

DiD = difference-in-differences. 
Table 7. The Impact of the Beverage Tax on Consumption

\begin{tabular}{|c|c|c|c|c|}
\hline & \multicolumn{2}{|c|}{ Adults } & \multicolumn{2}{|c|}{ Children } \\
\hline & (A) & (B) & (A) & (B) \\
\hline $\begin{array}{l}\text { Frequency of } \\
\text { consumption }\end{array}$ & & & & \\
\hline All Taxed Beverages & $\begin{array}{c}-5.068 \\
(5.946) \\
{[404]}\end{array}$ & $\begin{array}{c}-4.374 \\
(6.043) \\
{[404]}\end{array}$ & $\begin{array}{c}-2.476 \\
(6.567) \\
{[371]}\end{array}$ & $\begin{array}{c}-4.316 \\
(5.920) \\
{[371]}\end{array}$ \\
\hline Regular Soda & $\begin{array}{c}-11.640 \\
(6.518) \\
{[425]}\end{array}$ & $\begin{array}{c}-10.397 \\
(5.670) \\
{[425]}\end{array}$ & $\begin{array}{c}0.246 \\
(3.475) \\
{[398]}\end{array}$ & $\begin{array}{c}-0.159 \\
(2.787) \\
{[398]}\end{array}$ \\
\hline Diet Soda & $\begin{array}{c}-1.689 \\
(1.304) \\
{[426]}\end{array}$ & $\begin{array}{c}-1.982 \\
(1.260) \\
{[426]}\end{array}$ & $\begin{array}{c}-0.164 \\
(0.818) \\
{[406]}\end{array}$ & $\begin{array}{c}-0.256 \\
(0.814) \\
{[406]}\end{array}$ \\
\hline Sweetened fruit drinks & $\begin{array}{c}4.435 \\
(3.733) \\
{[418]}\end{array}$ & $\begin{array}{c}5.665 \\
(3.580) \\
{[418]}\end{array}$ & $\begin{array}{c}-1.119 \\
(4.484) \\
{[387]}\end{array}$ & $\begin{array}{c}-2.404 \\
(4.252) \\
{[387]}\end{array}$ \\
\hline Energy Drinks & $\begin{array}{l}\text { n.a. } \\
\text { n.a. } \\
\text { n.a. }\end{array}$ & $\begin{array}{l}\text { n.a. } \\
\text { n.a. } \\
\text { n.a. }\end{array}$ & $\begin{array}{c}-0.935 \\
(0.677) \\
{[213]}\end{array}$ & $\begin{array}{c}-0.890 \\
(0.662) \\
{[213]}\end{array}$ \\
\hline Untaxed Beverages & $\begin{array}{c}-3.249 \\
(15.524) \\
{[346]}\end{array}$ & $\begin{array}{c}-4.366 \\
(15.459) \\
{[346]}\end{array}$ & $\begin{array}{c}-10.534 \\
(20.425) \\
{[333]}\end{array}$ & $\begin{array}{c}-2.063 \\
(18.255) \\
{[333]}\end{array}$ \\
\hline Bottled Water & $\begin{array}{c}3.534 \\
(8.263) \\
{[411]}\end{array}$ & $\begin{array}{c}4.392 \\
(8.034) \\
{[411]}\end{array}$ & $\begin{array}{c}-0.855 \\
(7.653) \\
{[386]}\end{array}$ & $\begin{array}{c}0.029 \\
(7.180) \\
{[386]}\end{array}$ \\
\hline Coffee & $\begin{array}{c}-0.863 \\
(4.668) \\
{[412]}\end{array}$ & $\begin{array}{c}-1.811 \\
(4.618) \\
{[412]}\end{array}$ & $\begin{array}{l}\text { n.a. } \\
\text { n.a. } \\
\text { n.a. }\end{array}$ & $\begin{array}{l}\text { n.a. } \\
\text { n.a. } \\
\text { n.a. }\end{array}$ \\
\hline Juice & $\begin{array}{c}-1.762 \\
(6.064) \\
{[414]}\end{array}$ & $\begin{array}{c}0.112 \\
(5.387) \\
{[414]}\end{array}$ & $\begin{array}{c}-2.811 \\
(4.849) \\
{[387]}\end{array}$ & $\begin{array}{c}-0.654 \\
(4.226) \\
{[387]}\end{array}$ \\
\hline Milk & $\begin{array}{l}4.40 \\
(5.33)\end{array}$ & $\begin{array}{c}2.81 \\
(4.877)\end{array}$ & $\begin{array}{l}-4.038 \\
(8.341)\end{array}$ & $\begin{array}{l}-2.275 \\
(8.220)\end{array}$ \\
\hline
\end{tabular}


$[398] \quad[398] \quad[382] \quad[382]$

$\begin{array}{lcccc}\text { Grams of added } & -7.745 & -5.945 & -1.992 & -2.374 \\ \text { sugars } & (3.932) & (3.733) & (3.489) & (3.255) \\ & {[392]} & {[392]} & {[359]} & {[359]}\end{array}$

Notes: Specification A controls for baseline consumption. Specification B controls for gender, age, race, education, and household income. The figures represent the change in the outcome for households in Philadelphia relative to those in the comparison communities. Standard errors are in parentheses. Sample sizes are in brackets. The outcomes are grams of added sugars and the frequency of monthly consumption by beverage type. All regressions were estimated with sample weights and standard errors clustered at the store level.

n.a. = not applicable. We did not ask adults separate questions about consumption of energy drinks; energy drinks are included in the questions about sweetened fruit drinks. We collected information about coffee consumption among children, but very few responded that they drink any coffee. 
Table 8. The Impact of the Beverage Tax on Any Consumption and Daily Consumption

\begin{tabular}{|c|c|c|c|c|}
\hline & \multicolumn{2}{|c|}{ Adults } & \multicolumn{2}{|c|}{ Children } \\
\hline & Any & Daily & Any & Daily \\
\hline All Taxed Beverages & $\begin{array}{c}-0.054 \\
(0.029) \\
{[404]}\end{array}$ & $\begin{array}{c}-0.054 \\
(0.063) \\
{[404]}\end{array}$ & $\begin{array}{c}-0.003 \\
(0.060) \\
{[371]}\end{array}$ & $\begin{array}{c}0.032 \\
(0.058) \\
{[371]}\end{array}$ \\
\hline Regular Soda & $\begin{array}{c}-0.024 \\
(0.034) \\
{[425]}\end{array}$ & $\begin{array}{c}-0.111 \\
(0.059) \\
{[425]}\end{array}$ & $\begin{array}{c}0.017 \\
(0.036) \\
{[398]}\end{array}$ & $\begin{array}{c}0.028 \\
(0.047) \\
{[398]}\end{array}$ \\
\hline Diet Soda & $\begin{array}{c}-0.167 \\
(0.055) \\
{[426]}\end{array}$ & $\begin{array}{c}-0.028 \\
(0.024) \\
{[426]}\end{array}$ & $\begin{array}{c}-0.021 \\
(0.041) \\
{[406]}\end{array}$ & $\begin{array}{c}-0.021 \\
(0.022) \\
{[406]}\end{array}$ \\
\hline Sweetened fruit drinks & $\begin{array}{c}-0.006 \\
(0.042) \\
{[418]}\end{array}$ & $\begin{array}{c}-0.028 \\
(0.024) \\
{[426]}\end{array}$ & $\begin{array}{c}-0.058 \\
(0.064) \\
{[387]}\end{array}$ & $\begin{array}{c}-0.001 \\
(0.053) \\
{[387]}\end{array}$ \\
\hline Energy Drinks & $\begin{array}{l}\text { n.a. } \\
\text { n.a. } \\
\text { n.a. }\end{array}$ & $\begin{array}{l}\text { n.a. } \\
\text { n.a. } \\
\text { n.a. }\end{array}$ & $\begin{array}{c}-0.040 \\
(0.044) \\
{[213]}\end{array}$ & $\begin{array}{c}-0.023 \\
(0.024) \\
{[213]}\end{array}$ \\
\hline Untaxed Beverages & $\begin{array}{c}0.018 \\
(0.016) \\
{[346]}\end{array}$ & $\begin{array}{c}0.038 \\
(0.030) \\
{[346]}\end{array}$ & $\begin{array}{c}0.007 \\
(0.007) \\
{[333]}\end{array}$ & $\begin{array}{c}0.006 \\
(0.017) \\
{[333]}\end{array}$ \\
\hline Bottled Water & $\begin{array}{c}0.065 \\
(0.048) \\
{[411]}\end{array}$ & $\begin{array}{c}0.062 \\
(0.056) \\
{[411]}\end{array}$ & $\begin{array}{c}-0.036 \\
(0.048) \\
{[386]}\end{array}$ & $\begin{array}{c}0.069 \\
(0.062) \\
{[386]}\end{array}$ \\
\hline Coffee & $\begin{array}{c}-0.039 \\
(0.041) \\
{[412]}\end{array}$ & $\begin{array}{c}-0.080 \\
(0.068) \\
{[412]}\end{array}$ & $\begin{array}{l}\text { n.a. } \\
\text { n.a. } \\
\text { n.a. }\end{array}$ & $\begin{array}{l}\text { n.a. } \\
\text { n.a. } \\
\text { n.a. }\end{array}$ \\
\hline Juice & $\begin{array}{c}0.107 \\
(0.041) \\
{[414]}\end{array}$ & $\begin{array}{c}0.077 \\
(0.064) \\
{[414]}\end{array}$ & $\begin{array}{c}0.030 \\
(0.030) \\
{[387]}\end{array}$ & $\begin{array}{c}0.043 \\
(0.064) \\
{[387]}\end{array}$ \\
\hline Milk & $\begin{array}{c}0.038 \\
(0.047) \\
{[398]}\end{array}$ & $\begin{array}{c}-0.034 \\
(0.060) \\
{[398]}\end{array}$ & $\begin{array}{c}0.017 \\
(0.030) \\
{[382]}\end{array}$ & $\begin{array}{c}0.036 \\
(0.048) \\
{[382]}\end{array}$ \\
\hline
\end{tabular}


Notes: The figures represent the change in the probability of any consumption or daily consumption by beverage type for households in Philadelphia relative to those in the comparison communities. Standard errors are in parentheses. Sample sizes are in brackets. The outcomes are indicator variables for consuming any of the given beverage in the past month or daily consumption of the given beverage throughout the past month. All regressions are estimated with sample weights, and standard errors are clustered at the store level. Additional control variables include baseline consumption, gender, age, race, education, and household income. n.a. $=$ not applicable. We did not ask adults separate questions about consumption of energy drinks; energy drinks are included in the questions about sweetened fruit drinks. We collected information about coffee consumption among children, but very few responded that they drink any coffee. 


\begin{tabular}{|c|c|c|c|c|}
\hline & \multicolumn{2}{|c|}{ Grams of sugar per day } & \multicolumn{2}{|c|}{$\begin{array}{c}\text { Times consumed regular } \\
\text { soda per month }\end{array}$} \\
\hline & Adults & Children & Adults & Children \\
\hline \multicolumn{5}{|l|}{ Individual Characteristics } \\
\hline \multirow[t]{3}{*}{ African-American } & -8.053 & -7.961 & -14.577 & -2.523 \\
\hline & (5.939) & (4.079) & $(7.527)$ & $(2.947)$ \\
\hline & [392] & [359] & [425] & [398] \\
\hline \multirow[t]{3}{*}{ Hispanic } & 0.713 & 12.062 & 9.189 & 8.139 \\
\hline & $(7.250)$ & $(7.506)$ & $(13.277)$ & $(9.626)$ \\
\hline & [392] & [359] & [425] & [398] \\
\hline \multirow[t]{3}{*}{ Below FPL } & 2.594 & 0.946 & -5.579 & 6.382 \\
\hline & (6.859) & (5.992) & $(10.592)$ & $(4.762)$ \\
\hline & {$[373]$} & {$[344]$} & {$[406]$} & {$[380]$} \\
\hline \multirow{3}{*}{$\begin{array}{l}\text { Household Member Receives SNAP } \\
\text { Benefits }\end{array}$} & -4.284 & 1.843 & -5.138 & 3.681 \\
\hline & $(7.530)$ & $(4.806)$ & $(10.903)$ & $(4.766)$ \\
\hline & [386] & [355] & [419] & [393] \\
\hline \multirow{3}{*}{$\begin{array}{l}\text { Household Member Receives WIC } \\
\text { Benefits }\end{array}$} & -6.571 & 1.248 & -12.988 & 6.799 \\
\hline & (8.999) & $(6.485)$ & (10.786) & (5.736) \\
\hline & {$[388]$} & {$[357]$} & [420] & {$[396]$} \\
\hline \multirow{3}{*}{$\begin{array}{l}\text { Sample Adults Have Greater than a } \\
\text { High School Education }\end{array}$} & 0.246 & -1.271 & -6.984 & -2.416 \\
\hline & $(6.168)$ & $(3.350)$ & $(5.925)$ & (3.193) \\
\hline & {$[392]$} & [359] & {$[425]$} & {$[398]$} \\
\hline \multirow[t]{3}{*}{ Child is Over Age 10} & n.a. & -8.185 & n.a. & -1.718 \\
\hline & n.a. & (9.151) & n.a. & $(5.890)$ \\
\hline & n.a. & [359] & n.a. & [398] \\
\hline \multicolumn{5}{|l|}{ Attitudes Toward the Tax and SSBs } \\
\hline \multirow{3}{*}{$\begin{array}{l}\text { Sample Adult Supports Tax at } \\
\text { Baseline }\end{array}$} & 2.865 & n.a. & 4.18 & n.a. \\
\hline & (8.419) & n.a. & $(18.554)$ & n.a. \\
\hline & [341] & n.a. & [371] & п.а. \\
\hline \multirow{3}{*}{$\begin{array}{l}\text { Sample Adult Agrees that SSBs are } \\
\text { Bad for Health }\end{array}$} & -8.417 & n.a. & -12.471 & п.а. \\
\hline & (3.556) & n.a. & (4.884) & п.а. \\
\hline & [390] & n.a. & [423] & n.a. \\
\hline \multirow{3}{*}{$\begin{array}{l}\text { Sample Adult is Trying to Drink } \\
\text { Fewer SSBs }\end{array}$} & -4.313 & n.a. & -10.811 & n.a. \\
\hline & $(4.652)$ & n.a. & $(6.141)$ & n.a. \\
\hline & {$[392]$} & n.a. & {$[425]$} & n.a. \\
\hline \multicolumn{5}{|l|}{ Cross-border shopping } \\
\hline \multirow[t]{3}{*}{ Never Shops Outside Philadelphia } & -12.939 & n.a. & -9.212 & n.a. \\
\hline & (10.370) & n.a. & (13.509) & n.a. \\
\hline & [245] & n.a. & [266] & n.a. \\
\hline \multirow{3}{*}{$\begin{array}{l}\text { Lives Far from Philadelphia Border } \\
\text { (Top Quartile Based on Distance) }\end{array}$} & -7.816 & 11.811 & -16.797 & 11.483 \\
\hline & (7.759) & $(4.473)$ & $(8.442)$ & (5.398) \\
\hline & [384] & [352] & {$[414]$} & [390] \\
\hline
\end{tabular}


Notes: All regressions control for baseline consumption, gender, age, race, education, and household income. The figures represent the change in the outcome for the given subgroup in Philadelphia relative to those in the comparison communities. Standard errors are in parentheses. Sample sizes are in brackets. All regressions are estimated with sample weights and standard errors clustered at the store level.

n.a. $=$ not applicable. Some questions were asked only to adults. 
Figure 1. Impact of the Tax on Consumption of Added Sugars from SSBs (Adults)

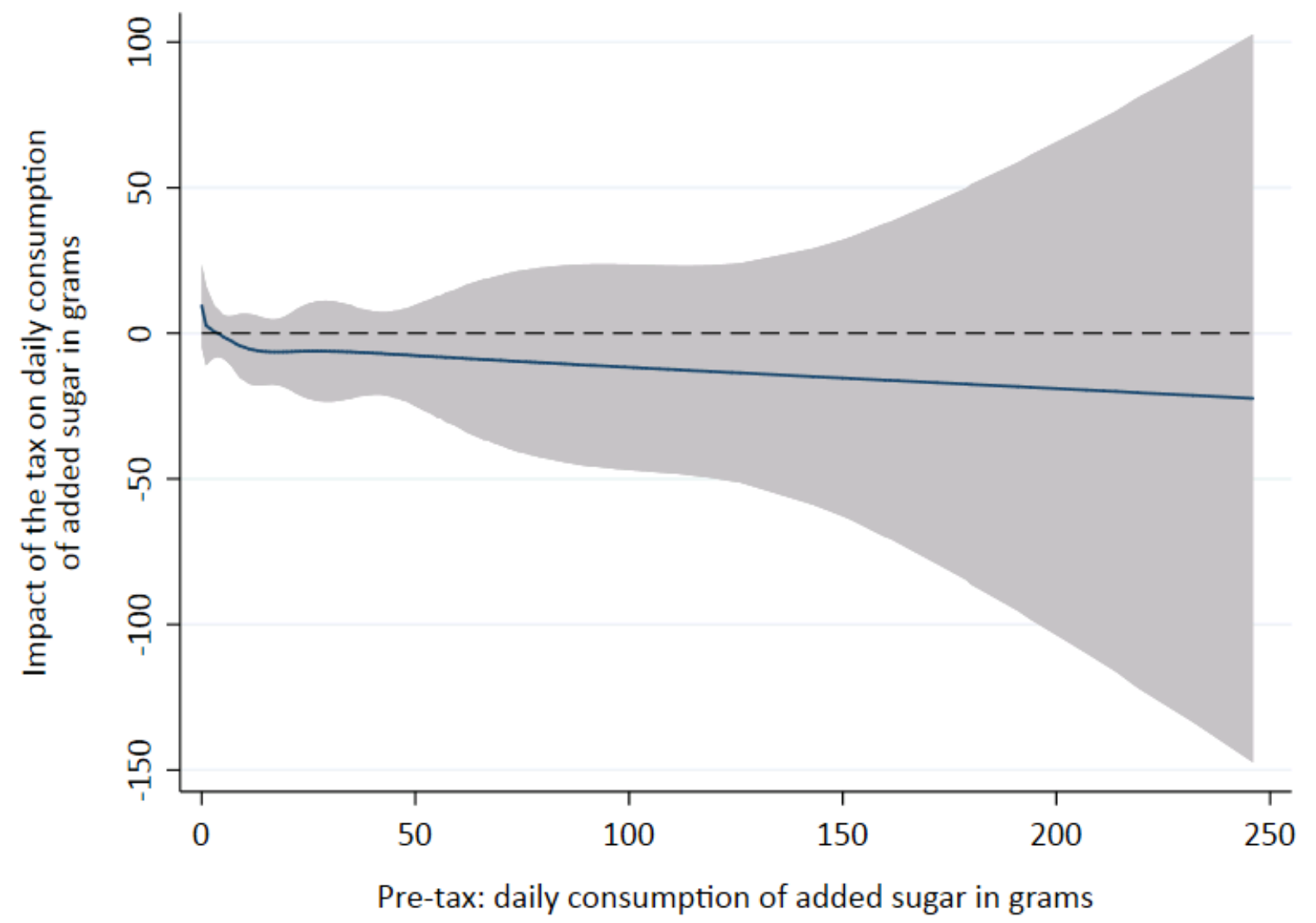

Notes: The solid line shows the impact of the tax for various levels of baseline consumption of added sugars. The shaded portion represents the 95 percent confidence interval for the impacts. 
Figure 2. Impact of the Tax on Consumption of Added Sugars from SSBs (Children)

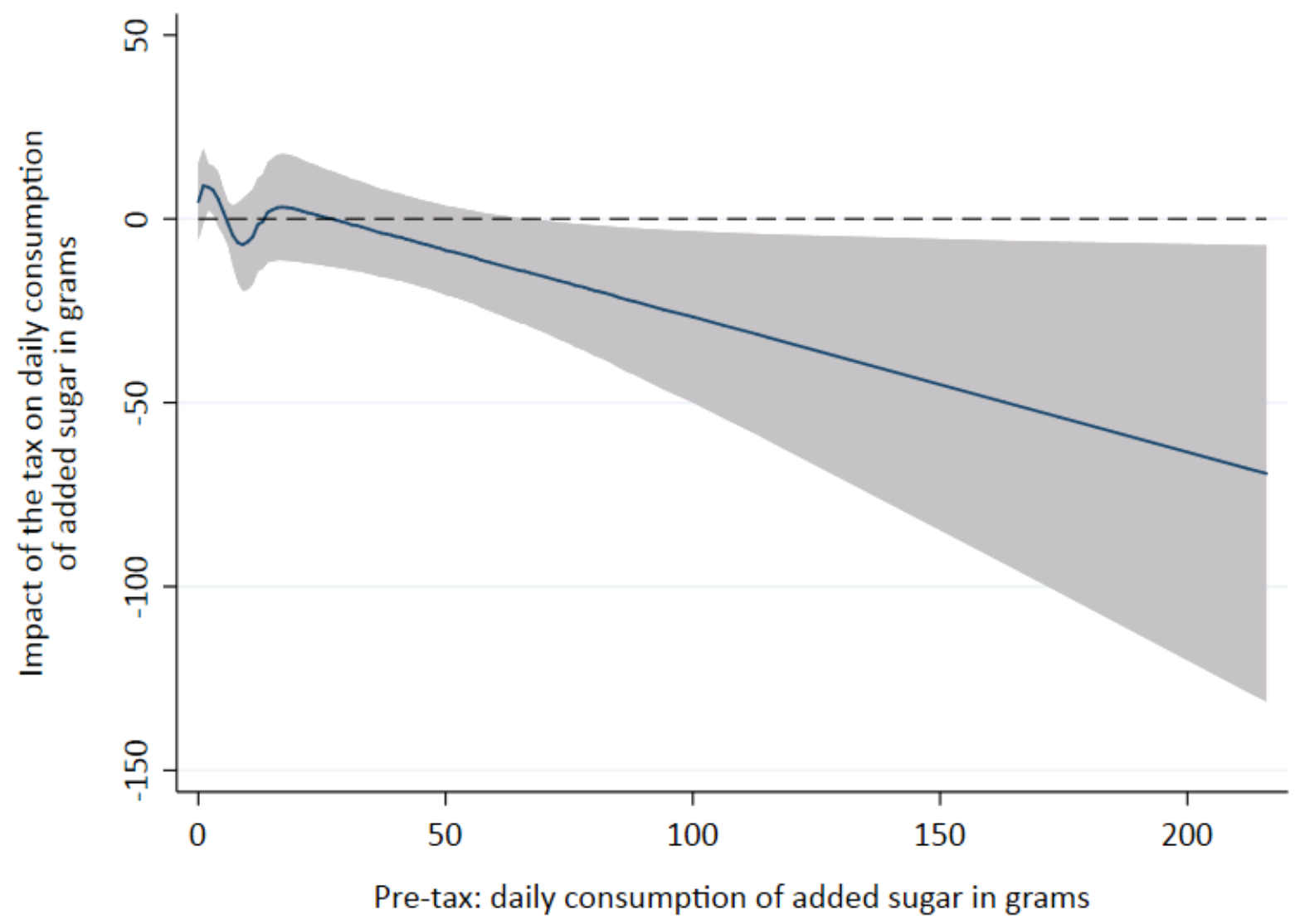

Notes: The solid line shows the impact of the tax for various levels of baseline consumption of added sugars. The shaded portion represents the 95 percent confidence interval for the impacts. 
Appendix Figure 1. Average Weekly Sales Volume per Store of Regular Soda, Diet Soda, and Juice Drinks in 2016

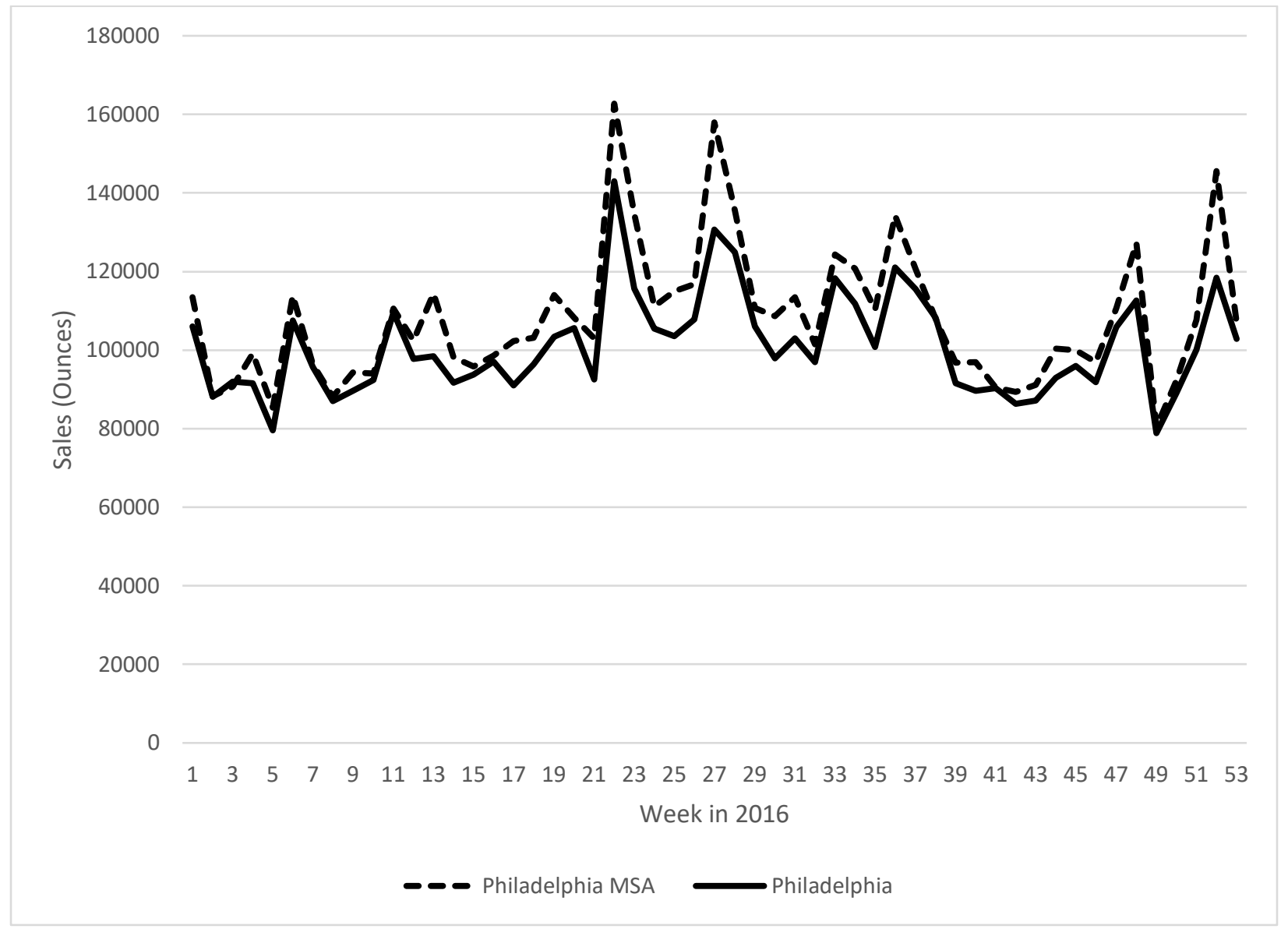

Notes: This figure shows the average weekly sales volume of regular soda, diet soda, and juice drinks per retail stores in Philadelphia and in the Philadelphia MSA throughout 2016. The conclusions drawn from the Nielsen data are those of the researchers and do not reflect the views of Nielsen. Nielsen is not responsible for, had no role in, and was not involved in analyzing and preparing the results reported herein.

Source: Researcher(s) own analyses calculated (or derived) based in part on data from The Nielsen Company (US), LLC and marketing databases provided through the Nielsen Datasets at the Kilts Center for Marketing Data Center at The University of Chicago Booth School of Business. 
Appendix Figure 2. Impact of the Tax on Monthly Consumption of Regular Soda (Adults)

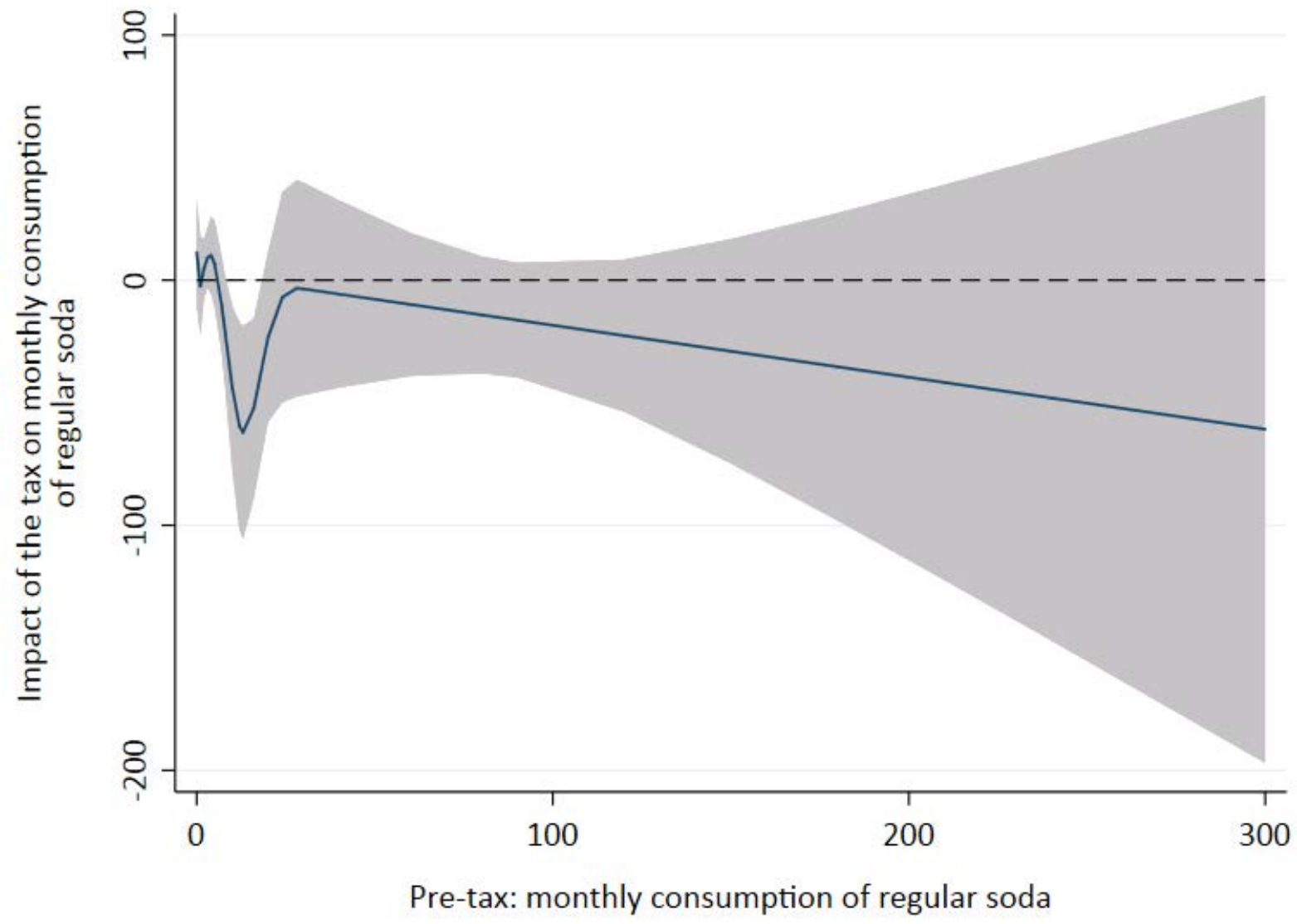

Notes: The solid line shows the impact of the tax for various levels of baseline monthly consumption of regular soda. The shaded portion represents the 95 percent confidence interval for the impacts. 
Appendix Figure 3. Impact of the Tax on Monthly Consumption of Regular Soda (Children)

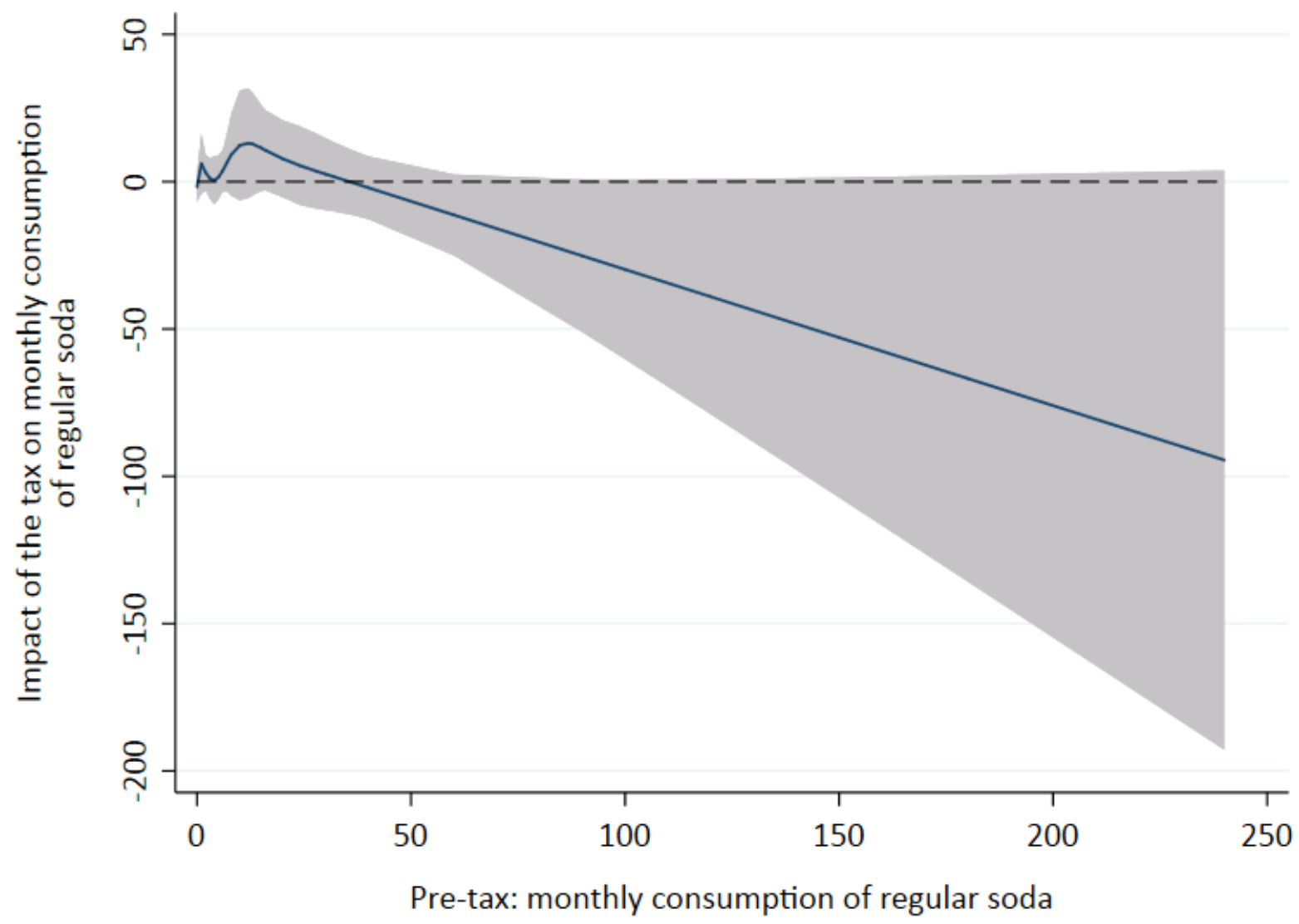

Notes: The solid line shows the impact of the tax for various levels of baseline monthly consumption of regular soda. The shaded portion represents the 95 percent confidence interval for the impacts. 